\title{
A genetic screen identifies dreammist as a regulator of sleep
}

4

Ida L. Barlow1,2, Eirinn Mackay1,3, Emily Wheater ${ }^{1,4}$, Aimee Goel ${ }^{1}$, Sumi Lim ${ }^{1}$, Steve Zimmerman $^{5}$, lan Woods ${ }^{6}$, David A. Prober ${ }^{7}$, and Jason Rihel ${ }^{1,{ }^{*}}$

${ }^{1}$ Department of Cell and Developmental Biology, University College London, UK;

${ }^{2}$ Current address: MRC London Institute for Medical Sciences, Imperial College London, UK

${ }^{3}$ Current address: Sainsbury Wellcome Centre for Neural Circuits and Behaviour, University College London, UK

${ }^{4}$ Current address: MRC centre for Reproductive Health, University of Edinburgh, UK

${ }^{5}$ Department of Molecular and Cellular Biology, Harvard University, USA

${ }^{6}$ Ithaca College, New York, USA

7 Division of Biology and Biological Engineering, California Institute of Technology, Pasadena, USA

* Lead author: Jason Rihel j.rihel@ucl.ac.uk

Significance statement: Sleep is an essential component of behaviour, but the genes that regulate sleep and wake states are still being uncovered. A viral insertion screen in zebrafish identified a novel sleep mutant called dreammist, in which a small, highly-conserved transmembrane protein is disrupted. The discovery of dreammist highlights the importance of a class of small transmembrane-protein modulators of the sodium pump in setting appropriate sleep duration. 


\section{Abstract}

Sleep is a nearly universal feature of animal behaviour, yet many of the molecular, genetic, and neuronal substrates that orchestrate sleep/wake transitions lie undiscovered. Employing a viral insertion sleep screen in larval zebrafish, we identified a novel mutant, dreammist (dmist), with altered sleep-wake dynamics. CRISPR/Cas9-mediated disruption of dmist also led to behavioural hyperactivity and reduced sleep at night. The neuronally expressed dmist gene is conserved across vertebrates and encodes a small single-pass transmembrane protein that is structurally similar to the $\mathrm{Na}^{+}, \mathrm{K}^{+}$-ATPase regulator, FXYD1/Phospholemman. Disruption of either fxyd1 or atp1a3a, a Na+, $\mathrm{K}^{+}-\mathrm{ATPase}$ alpha-3 subunit associated with several heritable movement disorders in humans, led to decreased night-time sleep. As intracellular $\mathrm{Na}^{+}$ concentration is disrupted in dmist mutant brains after high neuronal activity similarly to atp1a3a mutants, but is also elevated specifically at night, we propose that sleep-wake stability is modulated by Dmist-dependent changes to $\mathrm{Na}^{+}$pump function during sleep homeostatic challenge and at specific times of the day-night cycle.

\section{INTRODUCTION}

The ability for animals to switch between behaviourally alert and quiescent states is conserved across the animal kingdom (Cirelli, 2009; Joiner, 2016). Fundamental rules that govern the regulation of sleep-like states are shared across species, such as the role of circadian and homeostatic cues in regulating the time and amount of sleep, stereotyped postures, heightened arousal thresholds, and the ready reversibility to a more alert state (Joiner, 2016). The near ubiquity of behavioural sleep implies that it serves ancient functions and is subject to conserved regulatory processes. However, many key molecular components that modulate sleep and wake states remain undiscovered.

Over the past two decades, investigations into sleep and arousal states of genetically tractable model organisms, such as Drosophila melanogaster, C. elegans, and zebrafish have 
uncovered novel molecular and neuronal components of sleep regulation through gain- and loss-of-function genetic screens (reviewed in Barlow and Rihel, 2017; Sehgal and Mignot, 2011). The power of screening approaches is perhaps best exemplified by the first forward genetic sleep screen, which identified the potassium channel shaker as a critical sleep regulator in Drosophila (Cirelli et al., 2005). This result continues to have a lasting impact on the field, as not only did subsequent sleep screening efforts uncover the novel SHAKERregulator sleepless, (Koh et al., 2009), but investigations into SHAKER's beta subunit HYPERKINETIC ultimately revealed a critical role for this redox sensor linking metabolic function to sleep (Bushey et al., 2007; Kempf et al., 2019). Other Drosophila loss of function screens have highlighted the sleep-regulatory roles of the dopamine transporter, fumin, (Wu et al., 2008) and the Cullin-3 ubiquitin ligase adaptor, insomniac (Pfeiffenberger and Allada, 2012; Stavropoulos and Young, 2011), among others.

Disparate screening strategies across model organisms continue to unveil novel sleep modulators in both invertebrate and vertebrate model systems. For example, the roles of RFamide receptor DMSR-1 in stress-induced sleep in C. elegans (lannacone et al., 2017) and SIK3 kinase in modulating sleep homeostasis in mice (Funato et al., 2016) were identified in genetic screens. Moreover, a gain of function screening strategy in Drosophila revealed the novel sleep and immune regulator, nemuri (Toda et al., 2019), and a zebrafish overexpression screen uncovered the secreted neuropeptides Neuromedin $U$ and Neuropeptide $Y$, which decrease and increase sleep, respectively (Chiu et al., 2016; Singh et al., 2017). The continued success of screening strategies in revealing novel sleep-wake regulatory genes suggests that more sleep signals likely remain to be discovered.

1 One of the lessons from these genetic screens is that many of the uncovered genes play conserved roles across species-for example, Shaker also regulates mammalian sleep (Douglas et al., 2007) and RFamides induce sleep in worms, flies, and vertebrates (Lee et al., 
2017; Lenz et al., 2015). Nevertheless, not every invertebrate sleep-regulatory gene has a clear homolog in vertebrate species, while known human sleep/wake regulators, such as the narcolepsy-associated neuropeptide hypocretin/orexin and its receptors, lack invertebrate orthologs (Chemelli et al., 1999; Lin et al., 1999; Prober et al., 2006; Sakurai, 2013; Yokogawa et al., 2007). Therefore, genetic sleep screens in vertebrates are likely to provide added value in uncovering additional regulatory components required to control the initiation and amount of sleep.

While sleep screening in mammals is feasible (Funato et al., 2016), it remains an expensive and technically challenging endeavour. With its genetic tractability, availability of highthroughput sleep assays (Rihel and Schier, 2013), and conserved sleep genetics, such as the hypocretin, melatonin, and raphe systems (Gandhi et al., 2015; Oikonomou et al., 2019; Prober et al., 2006), the larval zebrafish offers an attractive alternative vertebrate system for sleep screens. We took advantage of a collection of zebrafish lines that harbour viral-insertions in $>3500$ genes (Varshney et al., 2013) to perform a targeted genetic screen. We found one short-sleeping mutant, dreammist, with a disrupted novel, highly conserved, vertebrate gene that encodes a small single pass transmembrane protein. Sequence and structural homology to the $\mathrm{Na}^{+} / \mathrm{K}^{+}$pump regulator FXYD1/Phospholemman suggests that Dreammist is a neuronalexpressed member of a class of sodium pump modulators that is important for regulating sleepwake behaviour. 


\section{Results}

\section{Reverse genetic screen identifies dreammist, a mutant with decreased sleep}

We used the availability of the 'Zenemark' viral-insertion based zebrafish gene knock-out resource (Varshney et al., 2013) to perform a reverse genetic screen to identify novel vertebrate sleep genes. This screening strategy offers several advantages compared to traditional chemical mutagenesis-based forward genetic screening approaches. First, unlike chemical mutagenesis, which introduces mutations randomly, viral insertions tend to target the 5' end of genes, typically causing genetic loss of function (Sivasubbu et al., 2007). Second, because the virus sequence is known, it is straightforward to map and identify the causative gene in mutant animals. Finally, since viral insertions in the Zenemark collection are already mapped and sequenced, animals harbouring insertions within specific gene classes can be selected for testing (Figure S1A). This allowed us to prioritise screening of genes encoding protein classes most often linked to behaviour, such as G-protein coupled receptors, neuropeptide ligands, and ion channels and transporters (Supplemental Data 1).

For screening, we identified zebrafish sperm samples from the Zenemark collection (Varshney et al., 2013) that harboured viral insertions in genes of interest and used these samples for in vitro fertilization and the establishment of F2 families. For each viral insertion line, clutches from heterozygous F2 in-crosses were raised to 5 days post-fertilisation (dpf) and tracked using videography (Figure S1A) to quantify the number and duration of sleep bouts and the average waking activity (time spent moving per one-minute active bouts) over 48 hours. The genotypes of individual larvae were determined by PCR after behavioural tracking, with each larva assigned as wild type, heterozygous, or homozygous for a given viral insertion to assess the effect of genotype on sleep/wake behaviour. While most lines screened had minimal effects on sleep-wake behavioural parameters (Figure S1B-C), one homozygous viral insertion line, 10543/10543, had a reduction in daytime sleep (Figure S1B) and an increase in daytime 
waking activity (Figure S1C) relative to their wild type sibling controls. We re-named this 10543 viral insertion line dreammist (dmist).

In follow-up studies, we observed that animals homozygous for the viral insertion at this

locus (dmistvir/vir) showed a prominent decrease in sleep during the day and a trend to sleep less at night compared to their wild-type siblings $\left({d m^{2}} t^{+/+}\right)$(Figure 1A). There was an almost $50 \%$ reduction in average daytime sleep (Figure $1 \mathrm{C}$ ) due to a decrease in the number of sleep bouts (Figure 1D), and sleep bout length at night was significantly reduced (Figure 1E). dmistvir/vir larvae also exhibited significantly increased daytime waking activity (Figure 1B, F). insertions; Varshney et al 2013), we outcrossed dmistvir/+ fish to wild-type fish of the AB-TL background and re-tested dmist mutant fish over several generations. Normalising all the behavioural parameters to $\mathrm{dmist}^{+/+}$controls with a linear mixed effects (LME) model showed reduction in the number and duration of sleep bouts, as well as a strong increase in waking activity (Figure 1G). The dmistvir/vir mutants also had a significant reduction in sleep at night compared to wild type siblings (Figure 1G). These effects on sleep and wakefulness are not due to alterations in circadian rhythms, as behavioural period length in fish that were entrained and then shifted to free-running constant dark conditions was unaffected in dmistvir/vir compared to wild-type sibling larvae (Figure S2A-C).

\section{The dmist gene encodes a novel, small transmembrane protein}

Having identified a sleep mutant, we next sought to investigate the target gene disrupted by

142 the viral insertion. Line 10543 (dmistvir) was initially selected for screening due to a predicted 143 disruption of a gene encoding a serotonin transporter (s/c6a4b) on chromosome 5. However, 
mapping of the dmist viral insertion site by inverse-PCR and sequencing revealed that the virus was instead inserted into the intron of a small two-exon gene originally annotated in the Zv6 genome assembly as a long intergenic non-coding RNA (lincRNA; gene transcript ENSDART00000148146, gene name si:dkey234h16.7), which lies approximately 6 kilobases $(\mathrm{kb})$ downstream of the $s / c 6 a 4 b$ gene in zebrafish. At least part of this region is syntenic across vertebrates, with a small two-exon gene consistently identified adjacent to the genes ankrd13a and GIT in several vertebrates, including human and mouse (Figure 2A). Amplifying both $5^{\prime}$ and 3' ends of zebrafish si:dkey234h16.7 and mouse E13.5 1500011B03-001 transcripts with Rapid Amplification of CDNA ends (RACE) confirmed the annotated zebrafish and mouse transcripts and identified two variants with 3' untranslated regions (3'UTR) of different lengths in zebrafish (Figure S3B). To test whether the viral insertion in dmistvir/vir disrupts expression of si:dkey234h16.7 or neighbouring genes, we performed quantitative analysis of gene transcript levels in wild type and mutant dmist larvae by RT-qPCR. This revealed that the dmist viral insertion caused a more than $70 \%$ knockdown in the expression of si:dkey234h16.7 while the expression of the most proximal 5' or 3' flanking genes, slc6a4b_Dr and ankrd13a_Dr, were unaffected (Figure 2B, Figure S3A). Since this disruption of expression is most consistent with si:dkey234h16.7 being the causal lesion of the dmist mutant sleep phenotype, we renamed this gene dreammist (dmist).

Although originally annotated as a lincRNA, computational predictions indicated that the dmist transcripts contain a small open reading frame (ORF) encoding a protein of 70 amino acids (aa) (Figure 2C, Figure S3B). Furthermore, mining of ribosome profiling datasets in zebrafish has shown that dmist is found in polyribosomes (Chew et al., 2013), and chromatin immunoprecipitation sequencing data (Pauli et al., 2015; Ulitsky et al., 2011) had identified that the locus contains histone methylation states associated with protein-coding genes (Aday et al., 2011). Incorporating this evidence, updated zebrafish genome assemblies (Zv9-11) have 
annotated dmist as a small protein-coding gene. Querying the human and vertebrate protein databases by BLASTp using the C-terminal protein sequence of Dmist identified orthologs in most other vertebrate clades, including other species of teleost fish, birds, amphibians, and mammals (Figure 2A, C). All identified orthologs encoded predicted proteins with an $\mathrm{N}$-terminal signal peptide sequence and a C-terminal transmembrane domain (Figure 2C). The peptide sequence identity across orthologs ranged from 38 to $84 \%$, with three peptide motifs (QNLV, CVYKP, RRR) showing high conservation across all vertebrates (Figure 2C, Figure S3D). In summary, we found that the dreammist gene, the expression of which is disrupted in dmistvirvir fish with sleep phenotypes, encodes a protein that is highly conserved across vertebrates at both the genomic and molecular levels.

\section{Genetic molecular analysis of dmist expression in zebrafish and mouse}

Because the viral insertion disrupts dmist throughout the animal's lifetime, we examined both the developmental and spatial expression of $d m i s t$ to assess when and where its function may be required for proper larval sleep. Using the full-length transcript as a probe (Figure S3B), we performed in situ hybridization across embryonic and larval development. Maternally deposited dmist was detected in early embryos (2-cell stage) prior to the maternal to zygotic transition (Giraldez et al., 2006) (Figure 2D). Consistent with maternal deposition of dmist transcripts, inspection of the 3' end of the dmist gene revealed a cytoplasmic polyadenylation element ('TTTTTTAT'; Supplemental Information 2) that is required for zygotic translation of maternal transcripts (Villalba et al., 2011). At 24hpf, transcripts were detected in regions that form the embryonic brain, such as ventral telencephalon, diencephalon and cerebellum, and in the developing eye (Figure 2D, S3C). By 5dpf, dmist transcripts were detected throughout the brain (Figure 2D). To test whether dmist transcripts are under circadian regulation, we performed RT-qPCR in fish that were entrained and then shifted to free-running constant dark 
conditions. In contrast with the robust 24-hr rhythmic transcription of the circadian clock gene per1, we did not detect any changes in dmist expression throughout the 24 hour circadian cycle (Figure S2D).

Consistent with brain expression in larval zebrafish, we identified the expression of Dmist_Mm in a published RNAseq dataset of six isolated cell types from mouse cortex (Zhang et al., 2014). We confirmed that Dmist_Mm is specifically enriched in neurons by hierarchical clustering of all 16,991 expressed transcripts across all six cells types, which demonstrated that Dmist_Mm co-clusters with neuronal genes (Figure S3E). Pearson correlation of Dmist_Mm with canonical markers for the six cell types showed that Dmist_Mm expression is highly correlated with other neuronal genes but not genes associated with microglia, oligodendrocytes, or endothelia. This indicates that dmist is specifically expressed in neurons in both zebrafish and mouse (Figure S3F).

\section{Dmist localises to the plasma membrane}

Although the dreammist gene encodes a conserved ORF with a predicted signal peptide sequence and transmembrane domain (Figure 2C; Figure S3G-I), we wanted to confirm this small peptide can localise to the membrane and if so, on which cellular compartments. To test these computational predictions, we transiently co-expressed GFP-tagged Dmist (C-terminal fusion) with a marker for the plasma membrane (myr-Cherry) in zebrafish embryos. Imaging at 90\% epiboly revealed Dmist-GFP localised to the plasma membrane (Figure 2E). Conversely, introducing a point mutation into Dmist's signal peptide cleavage site (DmistA22W-GFP) prevented Dmist from trafficking to the plasma membrane, with likely retention in the endoplasmic reticulum (Figure $2 \mathrm{~F}$ ). Together, these data indicate that Dmist localises to the plasma membrane despite its small size, as computationally predicted. 


\section{CRISPR/Cas9 generated dmist $^{i 8}$ mutant exhibits decreased night-time sleep}

The original viral insertion line had reduced dmist expression by $70 \%$, suggesting that

$d m i s t^{v i r}$ is a hypomorphic allele. To confirm that the sleep phenotypes observed in $d m i s t^{v i r / v i r}$

animals are due to the disruption of Dmist function, we used CRISPR/Cas9 to create an

223 independent dmist loss of function allele. We generated a zebrafish line in which the dmist

224 gene contains an 8bp insertion that causes a frameshift and early stop (dmisti8, Figure 3A).

225 The dmisti $^{i 8}$ allele is predicted to encode a truncated protein lacking the complete signal peptide

sequence and transmembrane domain (Figure 3B), indicating this is likely a null allele. RT-

qPCR showed that dmist transcript levels were $60 \%$ lower in $d m i s t^{i 8 / i 8}$ fish compared to wild type siblings, consistent with nonsense-mediated decay (Figure S4A, B).

We next assessed the sleep and activity patterns of dmisti8/i8 fish. As seen in exemplar individual tracking experiments, $d m i s t^{i 8 / i 8}$ larvae sleep less at night due to fewer sleep bouts as

well as an increase in waking activity relative to wild type and heterozygous mutant siblings

(Figure 3C-H). This significant night-time reduction in sleep and increase in wakefulness is also

apparent when combining $\mathrm{N}=5$ independent experiments with an LME model to normalize

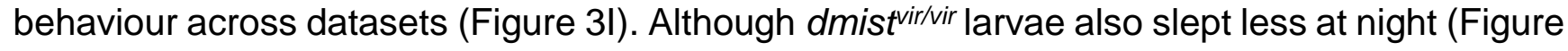

$1 \mathrm{G})$, the large day-time reduction in sleep observed in $d m i s t^{\text {vir/vir }}$ larvae is absent in $d m i s t^{i 8 / i 8}$

animals, perhaps because of differences in the dmist ${ }^{\text {vir }}$ genetic background affecting behaviour.

In addition, because the dmistir is likely a hypomorphic allele, we focused subsequent experiments on the CRISPR-generated $d m i s t^{i 8 / i 8}$ larvae.

To test whether the increased night-time activity of dmisti8/i8 mutants persists in older animals, we raised $d m i s t^{i 8 / i 8}$ mutants with their heterozygous and wild type siblings to adulthood

241 in the same tank and tracked individual behaviour for several days on a 14:10 light:dark cycle.

242 As in larval stages, dmisti8/i8 adults were hyperactive relative to both $d m i s t^{i 8 /+}$ and $d m i s t^{+/+}$ 
243 siblings, maintaining a higher mean speed at night (Figure 3L-M, S4D). This suggests that

244 either Dmist affects a sleep/wake regulatory circuit during development that is permanently 245 altered in dmist mutants or that Dmist is continuously required to maintain normal levels of 246 night-time locomotor activity.

dmist mutants have altered sleep homeostasis

The timing and duration of sleep is regulated by both circadian and homeostatic processes (Borbély, 1982). Since the disruption of dmist does not affect circadian regulation of sleep (Figure S2A-C), we tested whether dmist mutants have deficits in sleep homeostasis. such as the epileptogenic pentylenetetrazol (PTZ) or wake-promoting caffeine induces a dosedependent increase in homeostatic rebound sleep following drug washout that is phenotypically and mechanistically similar to rebound sleep following physical sleep deprivation (Reichert et al., 2019). Upon wash-on/wash-off of 5mM PTZ, sleep rebound occurs in approximately $50 \%$ of wild type larvae (Reichert et al., 2019; Figure $3 \mathrm{~K}$ ). In contrast, all $d m i s t^{i 8 / i 8}$ larvae showed increased rebound sleep compared to $d m^{2} s^{+/+}$sibling controls (Figure 3J, K, Figure S4C). Such sensitivity to sleep pressure induced by neuronal activity suggests that $d m i s t^{i 8 / i 8}$ fish either have accumulated high basal levels of sleep pressure, for example as 261 a consequence of extended wakefulness at night, or more rapidly accumulate sleep pressure 262 in response to increased brain activity during waking. This result indicates that $d m i s t^{i 8 / i 8}$ fish 263 have disrupted sleep homeostasis.

In summary, long-term tracking across both dmist alleles and assessment of responses to 265 drug-induced sleep pressure indicates that Dmist is a sensitive modulator of sleep/wake states. 


\section{Dmist is distantly related to the $\mathrm{Na}^{+} / \mathrm{K}^{+}$pump regulator Fxyd1 (Phospholemman)}

Because Dmist is a small, single pass transmembrane domain protein without any clear

regulate behaviour. Using the multiple sequence alignment tool MAFFT to align the zebrafish,

mouse, and human Dmist peptides (Katoh and Toh, 2010) and seeding a JackHMMR iterative

search of the Uniprot database (Johnson et al., 2010) found distant homology between Dmist

and Fxyd1/Phospholemman (Figure 4A), a small transmembrane domain peptide that

274

275

regulates ion channels and pumps, including the $\mathrm{Na}^{+}, \mathrm{K}^{+}$-ATPase pump (Crambert et al., 2002).

Dmist and Fxyd1 share 27-34\% amino acid homology, including an RRR motif at the C-terminal end, although Dmist lacks a canonical FXYD domain (Figure 4A). This similarity suggested that Dmist may belong to a class of small, single pass transmembrane ion pump regulators.

Using In situ hybridisation, we found that fxyd1 is expressed in cells along the brain ventricle and choroid plexus (Figure 4C) in contrast to the neuronal expression of dmist (Figure 2D). Despite these different expression patterns, based on their sequence similarity we reasoned that Fxyd1 and Dmist may regulate the same molecular processes that are involved in sleep. To test this hypothesis, we used CRISPR/Cas9 to generate a 28 bp deletion in the $3^{\text {rd }}$ exon of the zebrafish fxyd1 gene, causing a frameshift and severely truncated protein that lacks the FXYD, transmembrane, and C-terminal domains (Figure 4B). Contrary to a previous report based on morpholino knockdown (Chang et al., 2012), fxyd1 ${ }^{428 / \Delta 28}$ larvae were viable with no detectable defect in inflation of the brain ventricles. We therefore tested fxyd1 mutant larvae for sleep phenotypes. Like dmist mutants, fxyd1 ${ }^{\Delta 28 / \Delta 28}$ larvae slept less at night (Figure 4D-F). Interestingly, this sleep loss is mainly due to shorter sleep bouts (Figure 4F), indicating that fxyd1 mutants initiate sleep normally but do not properly maintain it, unlike dmist mutants, which initiate fewer night-time sleep bouts, although in both cases there is consolidation of the 
waking state at night (Figure $3 \mathrm{I}$ ). Thus, despite the non-neuronal expression of $f x y d 1$ in the brain, the gene most closely related to dmist also modulates sleep at night.

\section{The brain-wide $\mathrm{Na}^{+} / \mathrm{K}^{+}$pump alpha subunit Atp1a3a regulates sleep at night}

Given the similarity between Dmist and Fxyd1 and their effects on night-time sleep, we hypothesized that mutations in $\mathrm{Na}^{+} / \mathrm{K}^{+}$pump subunits known to interact with $\mathrm{Fxyd} 1$ might also affect sleep. We focused on the $\mathrm{Na}^{+} / \mathrm{K}^{+}$pump alpha-3 subunit (Atp1a3), as this has been shown to directly interact with Fxyd1 in mammalian brain tissue (Feschenko et al., 2003) and mutations in ATP1A3 in humans causes several neurological and movement disorders, including rapid-onset dystonia parkinsonism (De Carvalho Aguiar et al., 2004) and alternating hemiplegia of childhood (Heinzen et al., 2014, 2012). Murine Dmist expression correlates well with Atp1a3 distribution across 5 brain cell types in mouse $($ Pearson correlation coefficient $=$ 0.63). Zebrafish have two Atp1a3 paralogs, atp1a3a and atp1a3b. Similar to dmist, atp1a3a is widely expressed in the larval zebrafish brain (Figure 5C, compare to Figure 2D). While atp1a3b is also expressed in the zebrafish brain, its expression is more limited to regions of the midbrain and hindbrain (Figure 5C). To test whether these subunits are involved in regulating zebrafish sleep, we made CRISPR-targeted mutants of both atp1a3a and atp1a3b and isolated an allele with a 19 base deletion in atp1a3a and an allele with a 14 base deletion in atp1a3b. Both mutations are predicted to generate null alleles due to deletion of the start codon (Figure 5A, B). Both atp1a3a $a^{419 / 419}$ and atp $1 a 3 b^{114 / 414}$ mutant larvae were healthy and viable through early development, and, contrary to a previous report based on morpholino injections (Doğanli et al., 2013), neither mutant had defects in the inflation of their brain ventricles. Sleep-wake tracking experiments found that atp $1 a 3 b^{114 / \Delta 14}$ mutants were slightly more active during the day but did not have sleep phenotypes (Figure 5F, G). In contrast, mutation of atp1a3a resulted in large effects on sleep-wake behaviour. Compared to wild type 
and heterozygous siblings, atp $1 a 3 a^{119 / 419}$ mutants were hyperactive throughout the day and

317 night, and had a large reduction in sleep at night (Figure 5D, F). The night-time sleep reduction 318 was due to a reduction in the length of sleep bouts, as atp1a3a mutants even had a small 319 increase in the number of sleep bouts at night (Figure 5F).

The similar night-time reduction in sleep in dmist and atp1a3a mutants, combined with the 321 protein homology between Dmist and Fxyd1, suggested that Dmist may be involved in 322 regulating the $\mathrm{Na}^{+} / \mathrm{K}^{+}$pump. Consistent with this hypothesis, brains from both $d m i s t^{i 8 / i 8}$ and 323 atp1a3a $a^{\Delta 19 / \Delta 19}$ larvae had elevated intracellular sodium levels after exposure to PTZ (Figure $3245 \mathrm{G})$. Thus, neither dmist nor atp1a3a mutants were able to restore intracellular sodium balance 325 after sustained neuronal activity as quickly as wild type siblings. Consistent with the night326 specific alterations in sleep behaviour, we also found that baseline brain $\mathrm{Na}^{+}$levels in $d m i s t$ 327 mutants were significantly elevated at night but not during the day (Figure 5H). Collectively, 328 these data are consistent with the hypothesis that night-time sleep duration is affected by 329 changes in $\mathrm{Na}^{+} / \mathrm{K}^{+}$pump function and that Dmist is required for maintaining this function both 330 at night and after sustained neuronal activity. 
331

332

333

334

335

336

337

338

339

340

341

342

343

\section{Discussion}

\section{Genetic screening discovers dmist, a novel sleep-regulatory gene}

Using a reverse genetic viral screening strategy, we discovered a short-sleeping mutant, dmist, which has a disruption in a previously uncharacterized gene encoding a small transmembrane peptide. Given that the dmist mutant appeared within the limited number of lines that we screened, it is likely that many other sleep genes are still waiting to be discovered in future screens. In zebrafish, one promising screening strategy will be to employ CRISPR/Cas9 genome editing to systematically target candidate genes. Advances in the efficiency of this technology now makes it feasible to perform a CRISPR "F0 screen" in which the consequences of bi-allelic, gene-specific mutations are rapidly tested in the first generation, with only the most promising lines pursued in germline-transmitted mutant lines (Grunwald et al., 2019; Jao et al., 2013; Shah et al., 2015; Shankaran et al., 2017; Wu et al., 2018). CRISPR F0 screens could be scaled to systematically target the large number of candidate sleepregulatory genes identified through human GWAS studies and sequencing of human patients suffering from insomnia and neuropsychiatric disorders (Allebrandt et al., 2013; Jansen et al., 2019; Lek et al., 2016; Palagini et al., 2019).

\section{Dmist is related to the $\mathrm{Na}+\mathrm{K}+$ pump regulator Fxyd1}

The small Dmist transmembrane protein is highly conserved across vertebrates, expressed in neurons, and important for maintaining normal sleep levels. How can such a small, single pass transmembrane protein lacking any clear functional domains modulate the function of neurons and ultimately animal behaviour? The recognition that Dmist has sequence homology ( $35 \%$ amino acid similarity) and structural homology (e.g. signal peptide and single pass transmembrane domains; a conserved 'RRR' motif) to the $\mathrm{Na}^{+}, \mathrm{K}^{+}-\mathrm{ATPase}$ pump regulator Fxyd1 (Phospholemman) offers some important clues. 
Fxyd1/Phospholemman is a member of the FXYD protein family, of which there are seven mammalian members (Sweadner and Rael, 2000). Each of the FXYD proteins is small, members interact with alpha subunits of the $\mathrm{Na}^{+}, \mathrm{K}^{+}$ATPase to regulate the function of this pump, with individual family members expressed in different tissues to modulate $\mathrm{Na}+, \mathrm{K}+$ ATPase activity depending on the physiological needs of the tissue (Geering et al., 2003). In cardiac muscle, FXYD1 is thought to act as a hub through which various signalling cascades, such as PKA, PKC, or nitric oxide, can activate or inhibit $\mathrm{Na}^{+}$pump activity (Pavlovic et al., 2013). For example, FXYD1 is critical for mediating the increased $\mathrm{Na}^{+}$pump activity observed after $\beta$-receptor stimulation via cAMP-PKA signalling (Despa et al., 2008). Much less is known about FXYD1's role in non-cardiac tissue, although it is expressed in neurons in the mammalian cerebellum, the choroid plexus, and ependymal cells, where it interacts with all three alpha subunits of the $\mathrm{Na}^{+}, \mathrm{K}^{+}$ATPase (Feschenko et al., 2003).

In zebrafish, we also found that fxyd1 is expressed in cells around the ventricles and in the choroid plexus (Figure 4C), in contrast to dmist which is expressed in neurons throughout the brain. Despite the different expression patterns, mutation of each gene resulted in a similar reduction of sleep at night. However, unlike dmist mutants, which have fewer sleep bouts (i.e.

373 initiate sleep less) and an increase in waking locomotor activity, fxyd1 mutants have shorter sleep bouts (i.e. cannot maintain sleep) on average and do not have a locomotor activity 375 phenotype. Just as the various FXYD family members modulate the $\mathrm{Na}^{+} / \mathrm{K}^{+}$pump in different 376 tissue- and context-specific ways, this phenotypic variation between fxyd1 and dmist mutants 377 could be due to the different fxyd1 and dmist expression patterns, modulation kinetics of 378 pump/channel dynamics, or interaction with alternative accessory proteins or signal 379 transduction cascades. Nevertheless, the similar timing and magnitude of sleep reduction, 
combined with the structural similarity of Fxyd1 and Dmist, suggest that they may regulate similar sleep-related processes.

\section{Dmist, the sodium pump, and sleep}

The similarity between Dmist and FXYD1 led us to directly manipulate the $\mathrm{Na}^{+}, \mathrm{K}^{+}$ATPase to test its importance in sleep. The $\mathrm{Na}^{+}, \mathrm{K}^{+}$-ATPase is the major regulator of intracellular $\mathrm{Na}^{+}$in all cells and, by actively exchanging two imported $\mathrm{K}^{+}$ions for three exported $\mathrm{Na}^{+}$ions, is essential for determining cellular resting membrane potential (reviewed in Clausen et al., 2017). The $\mathrm{Na}^{+}, \mathrm{K}^{+}-\mathrm{ATPase}$ is made up of a catalytic alpha subunit (4 known isoforms, ATP1A14), a supporting beta subunit (3 isoforms, ATP1B1-3), and a regulatory gamma subunit (the FXYD proteins). The alpha1 and alpha3 subunits are the predominant catalytic subunits in neurons (alpha2 is mostly restricted to glia), although the alpha1 subunit is also used ubiquitously in all tissues (McGrail et al., 1991). By mutating zebrafish orthologs of Atp1a3, we therefore could test the neuronal-specific role of the $\mathrm{Na}^{+}, \mathrm{K}^{+}$-ATPase in sleep.

Mutations in both zebrafish Atp1a3 orthologs increased waking locomotor behaviour during the day. However, only mutations in the brain-wide atp1a3a, but not in the more restricted atp1a3b, led to changes in night-time sleep. The atp1a3a mutants have a bigger sleep reduction than either $d m i s t^{v i r}, d m i s t^{i 8}$ or $f x y d 1^{428}$ mutants, which is expected since increased phenotypic severity is a common feature of perturbations in ion channel/pump subunits compared to their modulators (Cirelli et al., 2005; Wu et al., 2014). Autosomal dominant missense mutations leading to loss of function in ATP1A3 cause movement disorders such as rapid-onset dystonia parkinsonism and childhood alternating hemiplegia (recurrent paralysis on one side) in humans (Canfield et al., 2002; Heinzen et al., 2014), while loss of function mutations in Atp1a3 result in generalised seizures and locomotor abnormalities, including 
404 hyperactivity, in mice (Clapcote et al., 2009; Hunanyan et al., 2015; Ikeda et al., 2013;

405 Kirshenbaum et al., 2011; Sugimoto et al., 2014). Our data also suggests that, in addition to

movement abnormalities, insomnia at night is a direct behavioural consequence of atp1a3a mutation, consistent with a recent report of very high prevalence of insomnia in patients with childhood alternating hemiplegia, some of which harboured mutations in Atp1a3 (Kansagra et al., 2019). Small molecule screens aimed at ameliorating zebrafish atp1a3a mutant phenotypes may therefore be a promising approach for the rapid identification of new therapies for the management of this disease (Hoffman et al., 2016; Rihel et al., 2010).

Together, the night-specific sleep phenotypes of dmist, fxyd1, and atp1a3a mutants point to a role for the $\mathrm{Na}^{+}, \mathrm{K}^{+}-$ATPase in boosting sleep at night. How might the alpha3 catalytic subunit of the $\mathrm{Na}^{+} / \mathrm{K}^{+}$pump regulate sleep, and how could Dmist be involved? Compared to the alpha1 subunit, Atp1a3 has a lower affinity for $\mathrm{Na}^{+}$ions, and therefore plays an essential role in repolarizing neurons in response to rapid $\mathrm{Na}^{+}$increases during high levels of neuronal activity (Azarias et al., 2013). We confirmed that Atp1a3a is essential in zebrafish for re-establishing proper brain intracellular $\mathrm{Na}^{+}$levels following high neuronal activity induced by the GABAreceptor antagonist, PTZ. Dmist is also essential for re-establishing brain $\mathrm{Na}^{+}$levels after PTZ exposure (Figure $5 \mathrm{G}$ ) but not during the baseline day conditions (Figure $5 \mathrm{H}$ ). Given that the intensity of global neuronal activity impacts the magnitude of subsequent sleep rebound and engagement of the Galanin sleep-homeostatic output arm (Reichert et al., 2019), this model of Dmist-Atp1a3a rebalancing $\mathrm{Na}^{+}$during high neuronal firing can also explain the observed exaggerated sleep rebound in dmist mutants following a short PTZ exposure (Figure $3 \mathrm{~J}$ ) as a consequence of increased neuronal depolarization due to defective $\mathrm{Na}^{+}$pump activity. Intriguingly, a meta-analysis of neuronal transcripts that increase during rodent sleep deprivation found mouse Dmist among the top responding genes (Stuart Peirson, personal communication), suggesting Dmist may play a similar role in regulating neuronal responses to 
physical sleep deprivation in mammals. Whether this transcriptional change reflects functional modulation of the $\mathrm{Na}^{+} / \mathrm{K}^{+}$pump in mammalian neurons awaits experimental validation.

We also found that Dmist is required for proper maintenance of brain intracellular $\mathrm{Na}^{+}$levels selectively at night but not during the baseline day, mirroring the timing of sleep disruption in $d m i s t^{i 8 / 8}$ animals. This suggests that the decreased night-time sleep of dmist mutants is due to a specific requirement for Dmist modulation of the $\mathrm{Na}^{+} / \mathrm{K}^{+}$pump at night. However, we cannot exclude the possibility that Dmist's function is required in only a subset of critical sleep/wake regulatory neurons during the day that then influence behaviour at night, such as the wakeactive, sleep-homeostatic regulating serotonergic neurons of the dorsal raphe (Oikonomou et al., 2019). Another possibility is that disruption of proper establishment of the $\mathrm{Na}^{+}$ electrochemical gradient in dmist mutant neurons leads to dysfunction of various neurotransmitter reuptake transporters, including those for glycine, GABA, glutamate, serotonin, dopamine, and norepinephrine, which rely on energy from the $\mathrm{Na}^{+}$gradient to function (Kristensen et al., 2011). A third possibility is that Dmist and the $\mathrm{Na}^{+}, \mathrm{K}^{+}-\mathrm{ATPase}$ regulate sleep not by modulation of neuronal activity per se but rather via modulation of extracellular ion concentrations. Recent work has demonstrated that interstitial ions fluctuate across the sleep/wake cycle in mouse; for example, extracellular $\mathrm{K}^{+}$is high during wakefulness (Ding et al., 2016). Moreover, cerebrospinal fluid containing the ion concentrations found during wakefulness directly applied to the brain can locally shift neuronal activity into wake-like states. Given that the $\mathrm{Na}^{+}, \mathrm{K}^{+}-\mathrm{ATPase}$ actively exchanges $\mathrm{Na}^{+}$ions for $\mathrm{K}^{+}$, the high intracellular $\mathrm{Na}^{+}$ levels we observe in atp1a3a and dmist mutants is likely accompanied by high extracellular $\mathrm{K}^{+}$. Although we can only speculate at this time, a model in which extracellular ions that accumulate during wakefulness and then directly signal onto sleep-regulatory neurons could provide a direct link between $\mathrm{Na}^{+}, \mathrm{K}^{+}$ATPase activity, neuronal firing, and sleep homeostasis. 
In conclusion, through a genetic screening strategy in zebrafish, we have identified a novel

454 brain expressed gene that encodes a small transmembrane protein regulator of night-time 455 sleep and wake behaviours. Future work will be required to uncover the precise signalling 456 dynamics by which Dmist regulates the $\mathrm{Na}^{+}, \mathrm{K}^{+}-\mathrm{ATP}$ ase and sleep.

\section{Acknowledgements}

458 The initial screen, discovery, and characterization of dreammist was conducted in the lab of 459 Alexander F Schier at Harvard University. We also would like to thank members of the Rihel 460 lab and other UCL zebrafish groups for helpful comments on experiments and the manuscript 461 over the years. We thank Shannon Shibata-Germanos for fxyd1 mutant tracking experiments, 462 John Parnavalas for reagents, Christine Orengo for help with small peptide sequence 463 searches, Stuart Peirson for early access to mouse transcriptomic data, and Finn Mango 464 Bamber for the Pokémon-card inspired dreammist name. The work was funded by grants 465 awarded to Alexander Schier, R01 GM085357 and HL10952505; an ERC Starting Grant 466 (\#282027) and Wellcome Trust Investigator Award (\#217150/Z/19/Z) to JR; National Institutes 467 of Health grant NS101158 to DAP; and a Grand Challenges PhD studentship to ILB. 
470

471

472

473

474

475

476

477

478

479

480

481

482

483

484

485

486

487

488

489

490

491

492

493

\section{References}

Aday, A.W., Zhu, L.J., Lakshmanan, A., Wang, J., and Lawson, N.D., 2011. Identification of cis regulatory features in the embryonic zebrafish genome through large-scale profiling of H3K4me1 and H3K4me3 binding sites. Dev. Biol. 357, 450-462. https://doi.org/10.1016/j.ydbio.2011.03.007

Allebrandt, K. V, Amin, N., Müller-Myhsok, B., Esko, T., Teder-Laving, M., Azevedo, R.V.D.M., Hayward, C., van Mill, J., Vogelzangs, N., Green, E.W., et al., 2013. A KATP channel gene effect on sleep duration: from genome-wide association studies to function in Drosophila. Mol. Psychiatry 18, 122-132. https://doi.org/10.1038/mp.2011.142

Azarias, G., Kruusmägi, M., Connor, S., Akkuratov, E.E., Liu, X.L., Lyons, D., Brismar, H., Broberger, C., and Aperia, A., 2013. A specific and essential role for Na,K-ATPase $\alpha 3$ in neurons co-expressing $\alpha 1$ and $\alpha 3$. J. Biol. Chem. 288, 2734-2743. https://doi.org/10.1074/jbc.M112.425785

Barlow, I.L., and Rihel, J., 2017. Zebrafish sleep: from geneZZZ to neuronZZZ. Curr. Opin. Neurobiol. 44, 65-71. https://doi.org/10.1016/j.conb.2017.02.009

Borbély, A.A., 1982. A two process model of sleep regulation. Hum. Neurobiol.

Bushey, D., Huber, R., Tononi, G., and Cirelli, C., 2007. Drosophila Hyperkinetic mutants have reduced sleep and impaired memory. J. Neurosci. 27, 5384-93. https://doi.org/10.1523/JNEUROSCI.0108-07.2007

Canfield, V.A., Loppin, B., Thisse, B., Thisse, C., Postlethwait, J.H., Mohideen, M.-A.P.., Rajarao, S.J.R., and Levenson, R., 2002. Na,K-ATPase $\alpha$ and $\beta$ subunit genes exhibit unique expression patterns during zebrafish embryogenesis. Mech. Dev. 116, 51-59. https://doi.org/10.1016/S0925-4773(02)00135-1

Chang, J.T., Lowery, L.A., and Sive, H., 2012. Multiple roles for the Na,K-ATPase subunits, 
494

495

496

497

498

499

500

501

502

503

504

505

506

507

508

509

510

511

512

513

514

515

516

517

Atp1a1 and Fxyd1, during brain ventricle development. Dev. Biol. 368, 312-22. https://doi.org/10.1016/j.ydbio.2012.05.034

Chemelli, R.M., Willie, J.T., Sinton, C.M., Elmquist, J.K., Scammell, T., Lee, C., Richardson, J.A., Clay Williams, S., Xiong, Y., Kisanuki, Y., et al., 1999. Narcolepsy in orexin knockout mice: Molecular genetics of sleep regulation. Cell 98, 437-451. https://doi.org/10.1016/S0092-8674(00)81973-X

Chew, G.-L., Pauli, A., Rinn, J.L., Regev, A., Schier, A.F., and Valen, E., 2013. Ribosome profiling reveals resemblance between long non-coding RNAs and 5' leaders of coding RNAs. Development 140, 2828-34. https://doi.org/10.1242/dev.098343

Chiu, C.N., Rihel, J., Lee, D.A., Singh, C., Mosser, E.A., Chen, S., Sapin, V., Pham, U., Engle, J., Niles, B.J., et al., 2016. A Zebrafish Genetic Screen Identifies Neuromedin U as a Regulator of Sleep/Wake States. Neuron 89, 842-856.

https://doi.org/10.1016/j.neuron.2016.01.007

Cirelli, C., 2009. The genetic and molecular regulation of sleep: from fruit flies to humans. Nat. Rev. Neurosci. 10, 549-60. https://doi.org/10.1038/nrn2683

Cirelli, C., Bushey, D., Hill, S., Huber, R., Kreber, R., Ganetzky, B., and Tononi, G., 2005. Reduced sleep in Drosophila Shaker mutants. Nature 434, 1087-1092. https://doi.org/10.1038/nature03486

Clapcote, S.J., Duffy, S., Xie, G., Kirshenbaum, G., Bechard, A.R., Schack, V.R., Petersen, J., Sinai, L., Saab, B.J., Lerch, J.P., et al., 2009. Mutation I810N in the a3 isoform of $\mathrm{Na}+, \mathrm{K}+-$ ATPase causes impairments in the sodium pump and hyperexcitability in the CNS. Proc. Natl. Acad. Sci. U. S. A. 106, 14085-14090.

https://doi.org/10.1073/pnas.0904817106

Clausen, M. V, Hilbers, F., and Poulsen, H., 2017. The Structure and Function of the Na,K- 
ATPase Isoforms in Health and Disease. Front. Physiol. 8, 371. https://doi.org/10.3389/fphys.2017.00371

Crambert, G., Fuzesi, M., Garty, H., Karlish, S., and Geering, K., 2002. Phospholemman (FXYD1) associates with Na,K-ATPase and regulates its transport properties. Proc. Natl. Acad. Sci. U. S. A. 99, 11476-81. https://doi.org/10.1073/pnas.182267299

De Carvalho Aguiar, P., Sweadner, K.J., Penniston, J.T., Zaremba, J., Liu, L., Caton, M., Linazasoro, G., Borg, M., Tijssen, M.A.J., Bressman, S.B., et al., 2004. Mutations in the $\mathrm{Na}+/ \mathrm{K}+-\mathrm{ATPase}$ a3 gene ATP1A3 are associated with rapid-onset dystonia parkinsonism. Neuron 43, 169-175. https://doi.org/10.1016/j.neuron.2004.06.028

Despa, S., Tucker, A.L., and Bers, D.M., 2008. Phospholemman-mediated activation of $\mathrm{Na/K}$ ATPase limits [Na]i and inotropic state during $\beta$-adrenergic stimulation in mouse ventricular myocytes. Circulation 117, 1849-1855. https://doi.org/10.1161/CIRCULATIONAHA.107.754051

Ding, F., O'donnell, J., Xu, Q., Kang, N., Goldman, N., and Nedergaard, M., 2016. Changes in the composition of brain interstitial ions control the sleep-wake cycle. Science (80-. ). 352, 550-555. https://doi.org/10.1126/science.aad4821

Doğanli, C., Beck, H.C., Ribera, A.B., Oxvig, C., and Lykke-Hartmann, K., 2013. a3Na+/K+ATPase deficiency causes brain ventricle dilation and abrupt embryonic motility in zebrafish. J. Biol. Chem. 288, 8862-8874. https://doi.org/10.1074/jbc.M112.421529

Douglas, C.L., Vyazovskiy, V., Southard, T., Chiu, S.-Y., Messing, A., Tononi, G., and Cirelli, C., 2007. Sleep in Kcna2 knockout mice. BMC Biol. 5, 42. https://doi.org/10.1186/17417007-5-42

Feschenko, M.S., Donnet, C., Wetzel, R.K., Asinovski, N.K., Jones, L.R., and Sweadner, K.J., 2003. Phospholemman, a single-span membrane protein, is an accessory protein 
of Na,K-ATPase in cerebellum and choroid plexus. J. Neurosci. 23, 2161-2169. https://doi.org/10.1523/jneurosci.23-06-02161.2003

Funato, H., Miyoshi, C., Fujiyama, T., Kanda, T., Sato, M., Wang, Z., Ma, J., Nakane, S., Tomita, J., Ikkyu, A., et al., 2016. Forward-genetics analysis of sleep in randomly mutagenized mice. Nature 539, 378-383. https://doi.org/10.1038/nature20142

Gagnon, J.A., Valen, E., Thyme, S.B., Huang, P., Ahkmetova, L., Pauli, A., Montague, T.G., Zimmerman, S., Richter, C., and Schier, A.F., 2014. Efficient Mutagenesis by Cas9 Protein-Mediated Oligonucleotide Insertion and Large-Scale Assessment of SingleGuide RNAs. PLoS One 9, e98186. https://doi.org/10.1371/journal.pone.0098186

Gandhi, A. V, Mosser, E.A., Oikonomou, G., and Prober, D.A., 2015. Melatonin Is Required for the Circadian Regulation of Sleep. Neuron 85, 1-7. https://doi.org/10.1016/j.neuron.2015.02.016

Geering, K., Béguin, P., Garty, H., Karlish, S., Füzesi, M., Horisberger, J.D., and Crambert, G., 2003. FXYD proteins: New tissue- and isoform-specific regulators of Na,K-ATPase, in: Annals of the New York Academy of Sciences. New York Academy of Sciences, pp. 388-394. https://doi.org/10.1111/j.1749-6632.2003.tb07219.x

Giraldez, A.J., Mishima, Y., Rihel, J., Grocock, R.J., Van Dongen, S., Inoue, K., Enright, A.J., and Schier, A.F., 2006. Zebrafish MiR-430 promotes deadenylation and clearance of maternal mRNAs. Science 312, 75-79. https://doi.org/10.1126/science.1122689

Grunwald, H.A., Gantz, V.M., Poplawski, G., Xu, X.R.S., Bier, E., and Cooper, K.L., 2019. Super-Mendelian inheritance mediated by CRISPR-Cas9 in the female mouse germline. Nature. https://doi.org/10.1038/s41586-019-0875-2

Heinzen, E.L., Arzimanoglou, A., Brashear, A., Clapcote, S.J., Gurrieri, F., Goldstein, D.B., Jóhannesson, S.H., Mikati, M.A., Neville, B., Nicole, S., et al., 2014. Distinct neurological 
disorders with ATP1A3 mutations. Lancet. Neurol. 13, 503-14.

Heinzen, E.L., Swoboda, K.J., Hitomi, Y., Gurrieri, F., De Vries, B., Tiziano, F.D., Fontaine,

Hoffman, E.J., Turner, K.J., Fernandez, J.M., Cifuentes, D., Ghosh, M., ljaz, S., Jain, R.A., Kubo, F., Bill, B.R., Baier, H., et al., 2016. Estrogens Suppress a Behavioral Phenotype ATP1A3 cause alternating hemiplegia of childhood. Nat. Genet. 44, 1030-1034. https://doi.org/10.1038/ng.2358

Hunanyan, A.S., Fainberg, N.A., Linabarger, M., Arehart, E., Leonard, A.S., Adil, S.M.,

lannacone, M.J., Beets, I., Lopes, L.E., Churgin, M.A., Fang-Yen, C., Nelson, M.D., Schoofs, Helseth, A.R., Swearingen, A.K., Forbes, S.L., Rodriguiz, R.M., et al., 2015. Knock-in mouse model of alternating hemiplegia of childhood: Behavioral and electrophysiologic L., and Raizen, D.M., 2017. The RFamide receptor DMSR-1 regulates stress-induced sleep in C. elegans. Elife 6. https://doi.org/10.7554/eLife.19837

Jansen, P.R., Watanabe, K., Stringer, S., Skene, N., Bryois, J., Hammerschlag, A.R., de 2013. Enhanced inhibitory neurotransmission in the cerebellar cortex of Atp1a3-deficient Leeuw, C.A., Benjamins, J.S., Muñoz-Manchado, A.B., Nagel, M., et al., 2019. Genomewide analysis of insomnia in 1,331,010 individuals identifies new risk loci and functional 
pathways. Nat. Genet. 51, 394-403. https://doi.org/10.1038/s41588-018-0333-3

591 Jao, L.-E., Wente, S.R., and Chen, W., 2013. Efficient multiplex biallelic zebrafish genome editing using a CRISPR nuclease system. Proc. Natl. Acad. Sci. U. S. A. 110, 13904-9. https://doi.org/10.1073/pnas. 1308335110

594 Johnson, L.S., Eddy, S.R., and Portugaly, E., 2010. Hidden Markov model speed heuristic and iterative HMM search procedure. BMC Bioinformatics 11, 431.

Joiner, W.J., 2016. Unraveling the Evolutionary Determinants of Sleep. Curr. Biol. 26,

Kansagra, S., Ghusayni, R., Kherallah, B., Gunduz, T., McLean, M., Prange, L., Kravitz, 600 R.M., and Mikati, M.A., 2019. Polysomnography findings and sleep disorders in children with alternating hemiplegia of childhood. J. Clin. Sleep Med. 15, 65-70.

Katoh, K., and Toh, H., 2010. Parallelization of the MAFFT multiple sequence alignment program. Bioinformatics. https://doi.org/10.1093/bioinformatics/btq224

Kempf, A., Song, S.M., Talbot, C.B., and Miesenböck, G., 2019. A potassium channel $\beta$ subunit couples mitochondrial electron transport to sleep. Nature 568, 230-234.

Kimmel, C.B., Ballard, W.W., Kimmel, S.R., Ullmann, B., and Schilling, T.F., 1995. Stages of embryonic development of the zebrafish. Dev. Dyn. 203, 253-310. https://doi.org/10.1002/aja.1002030302

Kirshenbaum, G.S., Clapcote, S.J., Duffy, S., Burgess, C.R., Petersen, J., Jarowek, K.J., Yücel, Y.H., Cortez, M.A., Snead, O.C., Vilsen, B., et al., 2011. Mania-like behavior induced by genetic dysfunction of the neuron-specific $\mathrm{Na}+, \mathrm{K}+-\mathrm{ATP} a \mathrm{se}$ a 3 sodium pump. 
Proc. Natl. Acad. Sci. U. S. A. 108, 18144-18149.

https://doi.org/10.1073/pnas.1108416108

Koh, K., Joiner, W.J., Wu, M.N., Yue, Z., Smith, C.J., and Sehgal, A., 2009. Identification of SLEEPLESS, a novel sleep promoting factor. Science (80-. ). 321, 372-376. https://doi.org/10.1126/science.1155942.Identification

Kristensen, A.S., Andersen, J., Jorgensen, T.N., Sorensen, L., Eriksen, J., Loland, C.J., Stromgaard, K., and Gether, U., 2011. SLC6 neurotransmitter transporters: Structure, function, and regulation. Pharmacol. Rev. 63, 585-640. https://doi.org/10.1124/pr.108.000869

Kwan, K.M., Fujimoto, E., Grabher, C., Mangum, B.D., Hardy, M.E., Campbell, D.S., Parant, J.M., Yost, H.J., Kanki, J.P., and Chien, C.-B., 2007. The Tol2kit: a multisite gatewaybased construction kit for Tol2 transposon transgenesis constructs. Dev. Dyn. 236, 3088-99. https://doi.org/10.1002/dvdy.21343

Lee, D.A., Andreev, A., Truong, T. V., Chen, A., Hill, A.J., Oikonomou, G., Pham, U., Hong, Y.K., Tran, S., Glass, L., et al., 2017. Genetic and neuronal regulation of sleep by neuropeptide VF. Elife 6. https://doi.org/10.7554/eLife.25727

Lek, M., Karczewski, K.J., Minikel, E. V., Samocha, K.E., Banks, E., Fennell, T., O’DonnellLuria, A.H., Ware, J.S., Hill, A.J., Cummings, B.B., et al., 2016. Analysis of proteincoding genetic variation in 60,706 humans. Nature 536, 285-291. https://doi.org/10.1038/nature19057

Lenz, O., Xiong, J., Nelson, M.D., Raizen, D.M., and Williams, J.A., 2015. FMRFamide signaling promotes stress-induced sleep in Drosophila. Brain. Behav. Immun. 47, $141-$ 148. https://doi.org/10.1016/j.bbi.2014.12.028

Lin, L., Faraco, J., Li, R., Kadotani, H., Rogers, W., Lin, X., Qiu, X., de Jong, P.J., Nishino, S., 
Mignot, E., et al., 1999. The sleep disorder canine narcolepsy is caused by a mutation in the hypocretin (orexin) receptor 2 gene. Cell 98, 365-76. https://doi.org/10.1016/S00928674(00)81965-0

Love, M.I., Huber, W., and Anders, S., 2014. Moderated estimation of fold change and dispersion for RNA-seq data with DESeq2. Genome Biol. 15, 550. https://doi.org/10.1186/s13059-014-0550-8

McGrail, K.M., Phillips, J.M., and Sweadner, K.J., 1991. Immunofluorescent localization of three $\mathrm{Na}, \mathrm{K}-\mathrm{ATPase}$ isozymes in the rat central nervous system: Both neurons and glia can express more than one Na,K-ATPase. J. Neurosci. 11, 381-391. https://doi.org/10.1523/jneurosci.11-02-00381.1991

Montague, T.G., Cruz, J.M., Gagnon, J.A., Church, G.M., and Valen, E., 2014. CHOPCHOP: a CRISPR/Cas9 and TALEN web tool for genome editing. Nucleic Acids Res. gku410-. https://doi.org/10.1093/nar/gku410

Oikonomou, G., Altermatt, M., Zhang, R. wei, Coughlin, G.M., Montz, C., Gradinaru, V., and Prober, D.A., 2019. The Serotonergic Raphe Promote Sleep in Zebrafish and Mice. Neuron 103, 686-701.e8. https://doi.org/10.1016/j.neuron.2019.05.038

Palagini, L., Domschke, K., Benedetti, F., Foster, R.G., Wulff, K., and Riemann, D., 2019. Developmental pathways towards mood disorders in adult life: Is there a role for sleep disturbances? J. Affect. Disord. 243, 121-132. https://doi.org/10.1016/J.JAD.2018.09.011

Pauli, A., Valen, E., Lin, M.F., Garber, M., Vastenhouw, N.L., Levin, J.Z., Fan, L., Sandelin, A., Rinn, J.L., Regev, A., et al., 2012. Systematic identification of long noncoding RNAs expressed during zebrafish embryogenesis Systematic identification of long noncoding RNAs expressed during zebrafish embryogenesis 577-591. 
663 Pauli, A., Valen, E., and Schier, A.F., 2015. Identifying (non-)coding RNAs and small peptides: Challenges and opportunities. BioEssays 37, 103-112. https://doi.org/10.1002/bies.201400103

Pavlovic, D., Fuller, W., and Shattock, M.J., 2013. Novel regulation of cardiac Na pump via phospholemman. J. Mol. Cell. Cardiol. 61, 83-93. https://doi.org/10.1016/j.yjmcc.2013.05.002

Pfeiffenberger, C., and Allada, R., 2012. Cul3 and the BTB Adaptor Insomniac Are Key

Prober, D. a, Rihel, J., Onah, A. a, Sung, R.-J., and Schier, A.F., 2006. Hypocretin/orexin overexpression induces an insomnia-like phenotype in zebrafish. J. Neurosci. 26,

Reichert, S., Pavón Arocas, O., and Rihel, J., 2019. The Neuropeptide Galanin Is Required 13400-10. https://doi.org/10.1523/JNEUROSCI.4332-06.2006

Rihel, J., and Schier, A.F., 2013. Sites of action of sleep and wake drugs: insights from model organisms. Curr. Opin. Neurobiol. 23, 831-40. https://doi.org/10.1016/j.conb.2013.04.010

Rihel, J., Prober, D. a, Arvanites, A., Lam, K., Zimmerman, S., Jang, S., Haggarty, S.J., Kokel, D., Rubin, L.L., Peterson, R.T., et al., 2010. Zebrafish behavioral profiling links drugs to biological targets and rest/wake regulation. Science 327, 348-51. https://doi.org/10.1126/science.1183090

Sakurai, T., 2013. Orexin deficiency and narcolepsy. Curr. Opin. Neurobiol. 23, 760-766. 
Sehgal, A., and Mignot, E., 2011. Genetics of sleep and sleep disorders. Cell 146, 194-207.

Shah, A.N., Davey, C.F., Whitebirch, A.C., Miller, A.C., and Moens, C.B., 2015. Rapid https://doi.org/10.1038/nmeth.3360

Shankaran, S.S., Dahlem, T.J., Bisgrove, B.W., Yost, H.J., and Tristani-Firouzi, M., 2017. CRISPR/Cas9-Directed Gene Editing for the Generation of Loss-of-Function Mutants in

Singh, C., Rihel, J., and Prober, D.A., 2017. Neuropeptide Y Regulates Sleep by Modulating Noradrenergic Signaling. Curr. Biol. 27, 3796-3811.e5.

Sivasubbu, S., Balciunas, D., Amsterdam, A., and Ekker, S.C., 2007. Insertional mutagenesis

Stavropoulos, N., and Young, M.W., 2011. insomniac and Cullin-3 regulate sleep and wakefulness in Drosophila. Neuron 72, 964-76. https://doi.org/10.1016/j.neuron.2011.12.003

Sweadner, K.J., and Rael, E., 2000. The FXYD gene family of small ion transport regulators or channels: cDNA sequence, protein signature sequence, and expression. Genomics 
711 Thisse, C., and Thisse, B., 2008. High-resolution in situ hybridization to whole-mount

Toda, H., Williams, J.A., Gulledge, M., and Sehgal, A., 2019. A sleep-inducing gene, nemuri, links sleep and immune function in Drosophila. Science 363, 509-515.

Ulitsky, I., Shkumatava, A., Jan, C.H., Sive, H., and Bartel, D.P., 2011. Conserved function of https://doi.org/10.1126/science.aat1650

Varshney, G.K., Lu, J., Gildea, D.E., Huang, H., Pei, W., Yang, Z., Huang, S.C., Schoenfeld, lincRNAs in vertebrate embryonic development despite rapid sequence evolution. Cell

Villalba, A., Coll, O., and Gebauer, F., 2011. Cytoplasmic polyadenylation and translational control. Curr. Opin. Genet. Dev. 21, 452-457. https://doi.org/10.1016/j.gde.2011.04.006

Wilkinson, R.N., Elworthy, S., Ingham, P.W., and van Eeden, F.J.M., 2013. A method for high-throughput PCR-based genotyping of larval zebrafish tail biopsies. Biotechniques

Wu, M., Robinson, J.E., and Joiner, W.J., 2014. SLEEPLESS Is a Bifunctional Regulator of Excitability and Cholinergic Synaptic Transmission. Curr. Biol. 24, 621-629. and Circadian Mutants Reveals Mechanisms Underlying Regulation of Sleep in Drosophila. Sleep 31, 465-472. https://doi.org/10.1093/sleep/31.4.465 
734 Wu, R.S., Lam, I.I., Clay, H., Duong, D.N., Deo, R.C., and Coughlin, S.R., 2018. A Rapid 125.e4. https://doi.org/10.1016/j.devcel.2018.06.003

Yokogawa, T., Marin, W., Faraco, J., Pézeron, G., Appelbaum, L., Zhang, J., Rosa, F., Mourrain, P., and Mignot, E., 2007. Characterization of sleep in zebrafish and insomnia in hypocretin receptor mutants. PLoS Biol. 5, e277.

741 Zhang, Y., Chen, K., Sloan, S.A., Bennett, M.L., Scholze, A.R., O’Keeffe, S., Phatnani, H.P., 742 Guarnieri, P., Caneda, C., Ruderisch, N., et al., 2014. An RNA-sequencing transcriptome and splicing database of glia, neurons, and vascular cells of the cerebral cortex. J. 
MATERIALS AND METHODS

Zebrafish husbandry

All zebrafish lines were housed on a 14hr:10hr light:dark schedule in dechlorinated water at

$27.5^{\circ} \mathrm{C}$ and routine husbandry was performed by the UCL Zebrafish Facility. Embryos were 752 collected from spontaneous spawning and staged according to Kimmel et al. 1995.

753 Embryos and larvae were raised on a 14hr:10hr light:dark schedule in 10cm Petri dishes at 754 a density of 50 embryos per $10 \mathrm{~cm}$ Petri dish. Embryo water ( pH7.3, temperature $28.5^{\circ} \mathrm{C}$, 755 conductivity $\sim 423.7$ uS with methylene blue) was changed daily and animals over 4 days post 756 fertilisation were euthanized by overdose of MS-222 (300 mg/l) or 15\% 2-Phenoyethanol 757 (77699 SIGMA-ALDRICH) at the end of experiments.

Raising of genetically altered zebrafish and all experimental procedures were performed 759 under project licence 70/7612 and PA8D4D0E5 awarded to JR under the UK Animals 760 (Scientific Procedures) Act 1986 guidelines.

Lines

\begin{tabular}{|c|c|c|}
\hline Strain designation & Gene identifier & Additional Information \\
\hline 10543/dmistvir & ENSDARG00000095754 & Line maintained at $\mathrm{J}$ Rihel lab \\
\hline dmisti8 & ENSDARG00000095754 & Line maintained at $\mathrm{J}$ Rihel lab \\
\hline$f x y d 1^{\Delta 28}$ & ENSDARG00000099014 & Line maintained at J Rihel lab \\
\hline atp $1 a 3 a^{\Delta 19}$ & ENSDARG00000018259 & Line maintained at $\mathrm{J}$ Rihel lab \\
\hline atp1a3b-14 & ENSDARG00000104139 & Line maintained at J Rihel lab \\
\hline
\end{tabular}

Table 1. Zebrafish lines 
763

The dmistvir allele was generated in wild type line T/AB-5 (Varshney et al., 2013) and 764 outcrossed to Harvard $A B$. The dmistis, fxyd1 ${ }^{\Delta 28}$, atp $1 a 3 a^{\Delta 19}$, and atp1a3b ${ }^{\Delta 14}$ alleles were 765 766 generated and maintained at UCL on an AB/TL background. Both $d m i s t^{i 8}$ and $d m i s t^{v i r}$ were outcrossed to the $A B$ strain at $U C L$ for 3 generations.

\section{Larval Tracking}

At 4 days post fertilisation (dpf), zebrafish larvae were placed into individual wells of a 96square well plate (WHA7701-1651 Sigma-Aldrich) filled with $650 \mu \mathrm{l}$ of embryo water per well and tracked for 3 days under a 14:10 light:dark schedule (lights on-09:00, lights off-23:00) using automated videotracking in ViewPoint ZebraBoxes (Viewpoint Life Sciences). The 96-well plate was under constant illumination with infrared LEDs, and white LEDs simulated the light:dark schedule. Videography (with one-third inch Dragonfly2 PointGrey monochrome camera, frame rate: $25-30 \mathrm{~Hz}$; fixed-angle megapixel lens, Computar M5018-MP) of individual larval activity was recorded in quantization mode to detect movement by background subtraction between frames in individual wells with 60 second integration time bins. Parameters used for detection 777 were calibrated according to the sensitivity of individual boxes but were in the following range: 778 detection threshold, 15-20; burst, 50 pixels; freeze, 3-4 pixels. Embryo water in the wells was 779 topped up daily with fresh water, and ambient room temperature was maintained at 780 approximately $26^{\circ} \mathrm{C}$. Output data was sorted, parsed and analysed by custom Perl and Matlab 781 scripts (MATLAB R2016 version 9.1, The MathWorks), as in Rihel et al. 2010.

Oxygen-permeable lids (Applied Biosystems 4311971) were applied over the top of the 96783 well plate when performing experiments in constant darkness, and the larvae were left 784 undisturbed for the duration of the experiment to avoid light exposure.

785 At the end of the experiment, all larvae were visually checked for health before euthanasia 786 and transfer to individual wells of a 96-well PCR plate for DNA extraction and genotyping. 


\section{Behavioural analysis}

Sleep parameters were calculated as in Rihel et al. 2010. Behavioural summaries across multiple experiments were determined by using the Matlab fitlme function to fit a linear mixed effects model for each parameter with genotype as a fixed effect and independent experiment as a random effect, then representing the effect size as a \% change from the wild type value. Before fitting the linear mixed effects model, the parameters sleep, sleep length, and waking activity were log normalized by calculating the log of $1+$ the parameter value for each larva.

Circadian period for every larvae was calculated using the Matlab findpeaks function on the activity (delta-pixels) timeseries data with a minimum peak distance of 18 hours (1080 minutes). N-way ANOVA was calculated to evaluate differences between groups.

\section{Code and data are available at https://github.com/ilbarlow/Dmist.}

\section{Adult tracking}

Fish from a $d m i s t^{i 8 /+} \times d m i s t^{i 8 /+}$ cross were raised in a mixed gender tank to adulthood.

Zebrafish adults (aged 3-4 months) were randomly selected and tracked on a 14:10 light:dark cycle (180 lux at water surface, lit from above) for three days as in (Chiu et al., 2016). In brief, fish were placed into uncovered plastic chambers $(7 \times 12 \times 8.5 \mathrm{~cm}$; WxLxH) with small holes for water exchange, and these were placed in a circulating water tank (46x54 cm with $4.5 \mathrm{~cm}$ water height). This setup was supplied with fish water from the home aquarium heated to $28^{\circ} \mathrm{C}$ and pumped from a $45 \mathrm{~L}$ reservoir at a flow rate of $1.3 \mathrm{~L} / \mathrm{min}$. Infrared light $(60$ Degree, $54 \mathrm{LED}$ Video Camera Red Infrared Illuminator Lamp, SourcingMap, with the ambient light detector covered) was continuously supplied from below. Fish were tracked at $15 \mathrm{~Hz}$ using Viewpoint Life Sciences ZebraBox tracking software in tracking mode, with a background threshold of 40 , inactive cut-off of $1.3 \mathrm{~cm} / \mathrm{sec}$, and a small movement cut-off of $8 \mathrm{~cm} / \mathrm{sec}$. Each track was visually inspected for errors at one-minute resolution across the entire session and analysed using custom Matlab scripts (MATLAB R2016 version 9.1, The Mathworks, Inc). During the 
812 tracking, the experimenter was blinded to genotype, which was determined by fin-clip after the

813 experiment. Females and males were originally analysed separately; since no significant 814 gender effect was found (two-way ANOVA, genotypeXgender), data from both genders were 815 pooled for the final analysis.

816 Genotyping

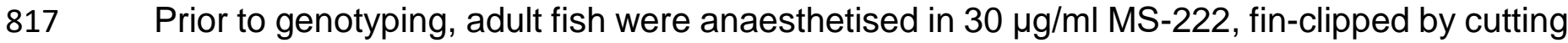
818 a small section of the caudal fin, and then allowed to recover in fresh fish water. For pooled experiments, 3dpf larvae from heterozygous in-crosses were fin-clipped as in Wilkinson et al., 2013 and allowed to recover in a square 96-well plate to keep larvae separate prior to pooling 821 larvae of the same genotype. Genomic DNA was extracted from adult fin clips and larvae by 822 boiling for 30 minutes in $50 \mu \mathrm{l}$ X base solution (0.025 M KOH, $0.2 \mathrm{mM}$ EDTA). Once cooled, 823 an equal volume $(50 \mu \mathrm{l})$ of neutralisation buffer $(0.04 \mathrm{M}$ Tris- $\mathrm{HCl})$ was then added and undiluted genomic DNA used for genotyping.

825 The dmist $t^{v i r}$ genotype was detected by PCR (standard conditions) using a cocktail of three 826 primers (0.36 $\mathrm{mM}$ final concentration each primer) to detect the wild type allele and viral 827 insertion (see Table 2) so that genotypes could be assigned according to size of bands 828 detected (dmistvir/vir 800bp; $d$ mist $^{\text {vir/+ }}$ 508bp and 800bp; $d m i s t^{+/+} 508 \mathrm{bp}$ ).

829 The dmistis genotype was assigned by KASP genotyping using allele-specific primers 830 (dmisti8 allele 5'-GATCTCCCT[GCAGAAAGAT]CTTTCTGCA-3' = FAM, dmist ${ }^{+}$allele 5'831 GATCTCCCT[CACCG]CTTTCTGCA-3' = HEX; KASP mastermix KBS-1016-011) and assay 832 were prepared and analysed according to manufacturer's protocol (LGC genomics).

833 The atp1a3a ${ }^{419}$ genotype was assigned by KASP genotyping using allele-specific primers 834 
835

836

837

838

839

840

841

842

843

844

845

846

847

848

849

850

851

852

853

854

855

856

857

858

GACAGACTGAAGAAACAGCGACTGACGGCTC[CAAAATGGGGGTAAGAGTC]-3' = FAM, atp 1a3a+ allele 5'-GACAGACTGAAGAAACAGCGACTGACGGCTC-3'[] = HEX).

The atp $1 a 3 b^{\Delta 14}$ genotype was assigned by PCR using MiSeq_atp1a3b primers (Table 2), with the atp $1 a 3 b^{\Delta 14}$ allele running $14 b p$ faster then the atp $1 a 3 b^{+}$allele.

$f x y d 1^{\Delta 28}$ was assigned by KASP genotyping using allele-specific primers ( $f x y d 1^{\Delta 28}$ allele $5^{\prime}$ GAAGGTCGGAGTCAACGGATTTAATAAACTTTATTGTGCTTTTGTAGTTGT[A]-3' = HEX, fxyd1+

allele

5'-

GAAGGTGACCAAGTTCATGCTTAATAAACTTTATTGTGCTTTTGTAGTTGT[G]-3’ = FAM) or PCR using MiSeq_fxyd1 primers (see Table 2) followed by digestion with the restriction enzyme Drdl, which yields bands at 138bp and 133bp for fxyd1+/+; 138bp, 133bp and 271bp for $f x y d 1^{+/ \Delta 28}$, and $243 b p$ for fxyd1 $1^{428}$.

\section{3'RACE}

FirstChoice RLM-RACE kit (Ambion AM1700) was used to amplify the 5' and 3' ends from cDNA obtained from 4dpf larvae raised on a 14:10 LD cycle and C57BL/6 E13.5 mouse embryos obtained from Parnavalas lab (UCL). 5' and 3'RACE primers were designed according the manufacturer's guidelines (Table 2) and the manufacturer's protocol was followed. Clones were sequenced by Sanger sequencing.

In situ hybridisation

Probes were designed to target the 3'UTR and entire open reading frame (ORF) of dmist_Dr transcript using primers that amplified the target region from zebrafish cDNA under standard PCR conditions (expected size 1325bp; Table 2). The PCR product was cloned into pSC vector (Strataclone PCR cloning kit Agilent 240205-12) and verified by Sanger sequencing. Antisense probe was generated by cleavage of pSC-dmist plasmid with Xbal and in vitro transcribed with T3 polymerase (Promega P2083) using $1 \mu \mathrm{g}$ DNA template according to standard in vitro 
859

transcription protocol (see full protocol at dx.doi.org/10.17504/protocols.io.ba4pigvn). RNA

probe was extracted and purified using ZYMO RNA concentrator kit (Zymo \#R1013).

Whole mount in situ hybridisation was performed according to (Thisse and Thisse, 2008) with the following adaptations. Embryos $<5 \mathrm{dpf}$ were dechorionated and fixed at the appropriate stage in $4 \%$ paraformaldehyde (PFA) overnight at $4{ }^{\circ} \mathrm{C}$. $5 \mathrm{dpf}$ larvae were fixed in $4 \% \mathrm{PFA} / 4 \%$ sucrose overnight at $4^{\circ} \mathrm{C}$ and then washed $3 \times 5$ mins in PBS prior to dissecting out the brain. Fixed embryos were washed $3 \times 5$ mins in PBS, progressively dehydrated into $100 \%$ methanol $(\mathrm{MeOH})$ and stored at $-20^{\circ} \mathrm{C}$ overnight. Prior to pre-hybridisation embryos were bleached for 30 mins in the dark $\left(0.05 \%\right.$ formamide, $\left.0.5 \mathrm{XSS}, 6 \% \mathrm{H}_{2} \mathrm{O}_{2}\right)$ and then fixed in $4 \%$ PFA for 30 mins at room temperature. To image, the embryos were progressively rehydrated into $0.1 \%$ PBTw, progressively sunk in to $80 \%$ glycerol, and imaged on Nikon compound microscope (Nikon Eclipse Ni, Leica MC190HD camera).

\section{$R T-q P C R$}

Larvae from heterozygous in-crosses (dmistib/+ or dmistvir/+) were genotyped at 3dpf and allowed to recover fully before euthanizing at $5 \mathrm{dpf}$. RNA was extracted from three $5 \mathrm{dpf}$ embryos of each genotype by snap freezing in liquid nitrogen and TRIzol RNA extraction (Ambion 15596026) with the following modifications to the manufacturer's protocol: $400 \mu \mathrm{l}$ total TRIzol reagent used to homogenise larvae using a pellet pestle homogenizer, and $5 \mu \mathrm{g}$ glycogen (Invitrogen Cat No. 10814010; $20 \mu \mathrm{g} / \mu \mathrm{l}$ ) was added to the RNA solution after chloroform extraction to aid precipitation of the RNA. The cDNA library was synthesised from high quality RNA (Agilent AffinityScript qPCR cDNA synthesis kit 600559), diluted 1:10, and gene-specific primers (Table 2) were used for amplification of target genes with SYBR green mastermix in BioRad CFX Real-Time qPCR instrument. The expression levels were normalised to the housekeeping gene EF1alpha (primers in Table 2) and analysed using custom Matlab scripts (MATLAB v9.2 2017, The Mathworks 2017). 
884

885

886

887

888

889

890

892

893

894

895

896

897

898

899

900

901

902

903

904

905

906

907

\section{Sodium Green Assay}

Cell permanent Sodium Green tetraacetate (Invitrogen, S6901) was prepared fresh from frozen stock by dissolving in DMSO to $1 \mathrm{mM}$ then diluting in fish water to a final concentration of $10 \mu \mathrm{M}$. About 50 larvae (5-7 dpf) from atp1a3a $a^{419 /+}$ or dmist ${ }^{i 8 /+}$ in-crosses were placed in wells of a 6 well plate, then most fish water was removed and replaced with $3 \mathrm{~mL}$ of the $10 \mu \mathrm{M}$ Sodium Green solution for two hours. During exposure, the plate was covered in foil and placed in a $28^{\circ} \mathrm{C}$ incubator. For PTZ experiments, larvae were also exposed to $10 \mathrm{mM} \mathrm{PTZ} \mathrm{(diluted}$ from $1 \mathrm{mM}$ stock dissolved in water) for two hours. For timepoints at night (ZT17-19), larvae were handled and collected under red light. After soaking in Sodium Green, larvae were washed 3X with fish water, anaesthetised with MS-2222, and fixed in 4\% PFA/4\% sucrose overnight at $4^{\circ} \mathrm{C}$. After $3 \mathrm{X}$ wash in PBS, larval brains were dissected and placed in $200 \mu \mathrm{L}$ PBS in a 48 well plate, and the matched bodies were used for genotyping (see Genotyping). Brains were imaged using an upright MVX10 MacroView microscope with an MC PLAPO 1x objective (both OLYMPUS) with a mercury lamp for fluorescent excitation at $488 \mathrm{~nm}$ (OLYMPUS, UHGLGPS). Images of roughly the same focal plane (dorsal/ventral view) were taken with an XM10 OLYMPUS camera by a single exposure following minimal light exposure (to avoid bleaching). Mean fluorescent intensity was calculated from ROls placed on the optic tectum/midbrain using ImageJ and normalized to the average fluorescence intensity for each imaging session.

\section{Protein Alignments}

Cross-species dmist homologues were identified by reciprocal BLASTp of C-terminal region of Dmist_Dr in vertebrate genomes. Translations of candidate transcript open reading frames were then aligned with Dmist_Dr using ClustalOmega to calculate the percentage identity matrix (www.ebi.ac.uk/Tools/msa/clustalo/) and visualised with the tool Multiple Align Show (www.bioinformatics.org/sms/multi align.html). 
To identify Dmist orthologues, Dmist peptides were aligned with the multiple sequence

alignment tool MAFFT (Katoh and Toh, 2010) and seeded into a JackHMMR iterative search

of the Uniprot database (Johnson et al., 2010). Protein-protein alignments of Dmist to Fxyd1

were then performed using ClustalOmega and visualized with the tool Multiple Align Show.

\section{CRISPR/Cas9 gene targeting}

CRISPR targets were designed and synthesised according to Gagnon et al., 2014 using ChopChop (Montague et al. 2014; http://chopchop.cbu.uib.no/; see Table 2 for sequences) to identify target sites. 100 pg sgRNA and 300 pg Cas9 mRNA (pT3TS-nCas9n) were injected into the yolk of 1-cell stage AB-TL embryos obtained from natural spawning. F0 fish were screened by high resolution melt (HRM) analysis using gene-specific primers (Table 2) with Precision melt supermix (Biorad 1725112) according to the manufacturer's protocol in a BioRad CFX RT-PCR thermocycler. Positive founders identified in HRM analysis were then sequenced by Illumina MiSeq sequencing using gene specific primers with adapters (Table 2) according to the manufacturer's protocol.

\section{Molecular cloning}

GFP was fused to the Dmist_Dr open reading frame (ORF) by Gateway cloning (Kwan et al., 2007). Gene-specific primers were designed to amplify a PCR product that was recombined with middle donor vector (Table 2; Invitrogen Gateway pDONR221 Cat No. 12536017, Invitrogen Gateway BP Clonase II Cat No. 11789020) to generate a middle entry clone (pMEDmist). pME-Dmist was recombined with 5' (p5E-CMV/SP6) and 3' (p3E-GFPpA) entry clones and destination vector (pDestTol2pA2) using Gateway Technology (Invitrogen LR Clonase II Plus enzyme Cat No. 12538200) following the manufacturer's protocol.

A 3bp mutation was introduced into the $C M V: d r e a m m i s t-G F P p A$ by inverse PCR using specific primers (Table 2) and KOD high fidelity hot start polymerase (Millipore 71085). The template was degraded by Dpnl digest and circular PCR product was transformed into 
933 OneShot TOP10 chemically competent E coli (Invitrogen C4040). Both CMV:dreammist934 GFPpA and CMV:dreammistA22W-GFPpA constructs were checked by Sanger sequencing. linearlised with Not1, in vitro transcribed with SP6 mMessage mMachine (Ambion AM1340), purified and quantified with a QuBit spectrophotometer, and injected at $0.04 \mu \mathrm{g} / \mu \mathrm{L}$.

938

dataset
The was downloaded from

954 (https://web.stanford.edu/group/barres_lab/brain_rnaseq.html; Zhang et al., 2014) and 955 hierarchical clustering (average linkage) and Pearson correlation calculation analysis were 956 performed using custom Matlab scripts (MATLAB v9.2 2017, The Mathworks 2017). 


\section{Experimental Design and Statistical Analyses}

958 Data was tested for normality using the Kolmogorov-Smirnov test. If data were normally 959 distributed, N-way ANOVA (alpha=0.05) was used with correction for multiple comparisons 960 using Tukey's test. If non-parametric, the Kruskal-Wallis test was used with correction for 961 multiple comparisons using Dunn-Sidak (alpha=0.05). Outliers were removed by Grubb's test 962 (threshold $p<0.01$ ). Data were grouped by genotype and gender for adult experiments and 963 grouped by genotype and day of experiment for larval experiments.

964 All code is available at https://github.com/ilbarlow/Dmist. 
bioRxiv preprint doi: https://doi.org/10.1101/2020.11.18.388736; this version posted December 6, 2020. The copyright holder for this

preprint (which was not certified by peer review) is the author/funder, who has granted bioRxiv a license to display the preprint in perpetuity. It is made available under aCC-BY 4.0 International license.

\section{Table 2. Primer Sequences}

\begin{tabular}{|c|c|c|c|c|}
\hline & Oligo Name & Sequence $\left(5^{\prime}->3^{\prime}\right)$ & $\begin{array}{c}\text { Annealing } \\
\text { temperature }(\mathrm{oC})\end{array}$ & Application \\
\hline 1 & dmist_vir_fw & CACAGGGATGTGATGCCGGTTAAC & 55 & dmistvir genotyping \\
\hline 2 & dmist_vir_rev & GTAGACACATACTGCCATACCAATC & 55 & dmistvir genotyping \\
\hline 3 & vir_fw & CACCAGCTGAAGCCTATAGAGTACGAGC- & 55 & dmistvir genotyping \\
\hline 5 & dmist_Dr_5RACE_rev_outer & AATGTTCAACTCCAGGCGTC & $55-65$ & dmist_Dr 5'RACE \\
\hline 6 & dmist Dr_5RACE rev inner & AATGTTCAACTCCAGGCGTC & $55-65$ & dmist Dr 5'RACE \\
\hline 7 & dmist_Dr_3RACE_fw_inner & GACGCCTGGAGTTGAACATT & $55-65$ & dmist_Dr 3'RACE \\
\hline 8 & dmist_Dr_3RACE_fw_outer & GGTATGGCAGTATGTGTCTACA & $55-65$ & dmist_Dr 3'RACE \\
\hline 9 & Dmist Mm 3RACE_outer & GCTGGTGACTGTCCTCCTTATG & $55-65$ & dmist Mm 3'RACE \\
\hline 10 & Dmist_Mm_3RACE_inner & GTGTCTACAAGCCCATCCGTC & $55-65$ & dmist_Mm 3'RACE \\
\hline 11 & dmist_Dr_fw & TTTCGCCACAATGTCAGCAGC & 56 & dmist_Dr probe \\
\hline 12 & dmist Dr_rev & CGACTTTCATTTATTAGTTCAGACATGTC & 56 & dmist Dr probe \\
\hline 13 & qPCR_dmist_fw & ACGCCAGACCTTATGAAATCC & 60 & RT-qPCR \\
\hline 14 & qPCR_dmist_rev & TGCGTCGGAGAGGTTTGTAG & 60 & RT-qPCR \\
\hline 15 & qPCR ankrd13a fw & TGGTGGCGTTCCAGAGTTAC & 60 & RT-qPCR \\
\hline 16 & qPCR_ankrd13a_rev & GGACACGAGAGGAATCCAGC & 60 & RT-qPCR \\
\hline 17 & qPCR_slc6a4b_fw & ACATGGTTGGGTCGACGTTT & 60 & RT-qPCR \\
\hline 18 & qPCR slc6a4b rev & TCCAACCCACCAAAAGTGCT & 60 & RT-qPCR \\
\hline 19 & ef1alpha_fw & TGCTGTGCGTGACATGAGGCAG & 60 & RT-qPCR \\
\hline 22 & T7atp1a3a_sgRNA & TAATACGACTCACTATAGACTGACGGCTCCAAAATGGGTTTTAGAGCTAGAAATAGCAAG & $\mathrm{n} / \mathrm{a}$ & CRISPR \\
\hline 23 & SP6fxyd1_sgRNA & ATTTAGGTGACACTATAGGACCCTCTGCCAACACAAGGTTTTAGAGCTAGAAATAGCAAG & $\mathrm{n} / \mathrm{a}$ & CRISPR \\
\hline 24 & SP6atp1a3b sgRNA & ATTTAGGTGACACTATAGGACTGACTGCGCAACCATGGTTTTAAGAGCTAGAAATAGCAAG & $\mathrm{n} / \mathrm{a}$ & CRISPR \\
\hline 25 & HRM dmist fw & GCCACAATGTCAGCAGCACG & 59 & HRM \\
\hline 26 & HRM_dmist_rev & GCGTTCACTTTAGACTCTCCCAGC & 59 & HRM \\
\hline 27 & HRM_atp1a3a_fw & TGACAGACTGAAGAAACAGC & 55 & HRM \\
\hline 28 & HRM atp1a3a rev & TTAAATCTCAGCACCAGCAG5 & 55 & HRM \\
\hline 29 & HRM_fxyd1_fw & TGACCAAACCTTCTTAAGGTGC & 58 & HRM \\
\hline 30 & HRM_fxyd1_rev & AAATTGAGAAGACTTACTGGTCTGC & 58 & HRM \\
\hline 31 & HRM atp $1 a 3 b$ fw & AAAGGCTGTCACTTTCTCCATCAC5 & 58 & HRM \\
\hline 32 & HRM_atp1a3b_rev & TGCAGTAGATGAGGAATCGGTC & 58 & HRM \\
\hline 33 & MiSeq_dmist_fw & TCGTCGGCAGCGTCAGATGTGTATAAGAGACAGTATAACTTACGTGTGGACGGACTC & 58 & MiSeq \\
\hline 34 & MiSeq_dmist rev & GTCTCGTGGGCTCGGAGATGTGTATAAGAGACAGTTGCCTCAGCAGGATTTCATAAG & 58 & MiSeq \\
\hline 35 & MiSeq_atp1a3a_fw & TCGTCGGCAGCGTCAGATGTGTATAAGAGACAGTCGTTATCCGTGCAAGAGCTTC & 58 & MiSeq \\
\hline 36 & MiSeq_atp1a3a_rev & GTCTCGTGGGCTCGGAGATGTGTATAAGAGACAGTTCTCAGCACCAGCAGTTATCG & 58 & MiSeq \\
\hline 37 & MiSeq_atp1a3b fw & TCGTCGGCAGCGTCAGATGTGTATAAGAGACAGTGACTGACATTCTCTCTTCGTG & 68 & MiSeq \\
\hline 38 & MiSeq_atp1a3b_rev & GTCTCGTGGGCTCGGAGATGTGTATAAGAGACAGTTCTCTGTGATGCAGTAGATGAGG & 68 & MiSeq \\
\hline 39 & MiSeq_fxyd1_fw & TCGTCGGCAGCGTCAGATGTGTATAAGAGACAGAAATACTGTCTTGTGACCAAACC & 57 & MiSeq \\
\hline 40 & MiSeq fxyd1 rev & GTCTCGTGGGCTCGGAGATGTGTATAAGAGACAGTTCATCCTCTGCTGCAAAATGC & 57 & MiSeq \\
\hline 44 & Dmist-GFPA22WRev & CTTTAGACTCTCCCAGCTGCCAACTCCCAGACTGGAAAAGC & 66 & SDM \\
\hline
\end{tabular}




\section{FIGURE LEGENDS}

\section{Figure 1. A viral insertion mini-screen identifies a short-sleeping mutant, dreammist.}

A-B) Representative 48hr mean sleep (A) and waking activity (B) traces of progeny from dmist ${ }^{\text {vir/t }}$ in-cross from the initial screened clutch. White blocks show day (lights on) and grey blocks show night (lights off). The ribbon around each trace indicates standard error of the mean.

C-F) Analysis of sleep/wake architecture of $d m i s t^{\text {vir/vir }}$ in the original screen during the day (white panel) and night (grey panel). C) Quantification of total sleep across two days and

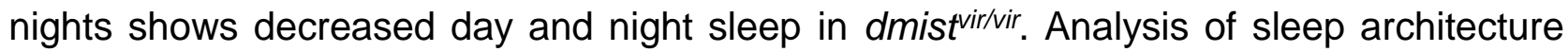
reveals fewer sleep bouts during the day (D) and shorter sleep bouts at night $(E)$ in $d m i s t^{\text {virvir }}$ compared with sibling controls. F) Daytime waking activity is also increased in dmistvir/vir. (dmist ${ }^{+/+} \mathrm{n}=38, d$ mist $^{\text {vir/+ }} \mathrm{n}=84, d$ mist $^{\text {vir/vir }} \mathrm{n}=19$ ). The black lines show the mean $\pm \mathrm{SEM}$, except in $\mathrm{E}$, which labels the median. ${ }^{*} \mathrm{p}<0.05,{ }^{* *} \mathrm{p}<0.01,{ }^{* * *} \mathrm{p}<0.001$; one-way ANOVA, Tukey's post hoc test.

G) Combining $\mathrm{N}=5$ independent tracking experiments using a linear mixed effects model with genotype as a fixed effect and experiment as a random effect reveals $d m i s t^{\text {vir/vir }}$ larvae have decreased total sleep and changes to sleep architecture during both the day and night compared to dmist $^{+/+}$siblings. Plotted are the genotype effect sizes $(95 \%$ confidence interval) on each parameter relative to wild type. Shading indicates day (white) and night (grey), and p-values are assigned by an F-test on the fixed effects coefficients from the linear mixed effects model. ${ }^{*} p<0.05,{ }^{* *} p<0.01,{ }^{* * *} p<0.001$, ns $p>0.05$ 


\section{Figure 2. dmist encodes a conserved vertebrate single pass transmembrane protein.}

A) dmist mutants harbour a viral insertion in the $1^{\text {st }}$ intron of si:key0234h16.7. dmist is syntenic with ankrd13 and GIT in mouse, human, and zebrafish.

B) Quantitative RT-qPCR of dmist (red) show reduced expression of dmist and not the 5' and 3' flanking zebrafish genes, slc6a4b (cyan) and ankrd13a (blue), in dmistvir/vir larvae compared to $d m i s t^{v i r /+}$ and $d m i s t^{+/+}$siblings. ${ }^{* *} \mathrm{p}<0.01,{ }^{*} \mathrm{p}<0.05$; one-way ANOVA, Tukey's post-hoc test. Data shows mean \pm SEM normalized to the wild type mean.

C) dmist_Dr contains an open reading frame encoding a 70 amino acid protein that is conserved across vertebrates. All identified homologues have a predicted signal peptide sequence (magenta line), signal peptide cleavage site (magenta circle), and predicted transmembrane domain (grey), with additional highly conserved C-terminal small peptide motifs (blue lines). Identical amino acids in all species are shown in black; similar amino acids (80-99\% conserved across species) are shown in grey.

D) In situ hybridisation using dmist antisense probe reveals dmist is maternally deposited as it is detected at the 2-cell stage. At $24 \mathrm{hpf}$ expression is restricted to regions containing neuronal precursors, and at $5 \mathrm{dpf}$ expression is widespread throughout the brain. Tel, telencephalon; Dien, diencephalon; R1-6, rhombomeres 1-6. Scale bars $=0.5 \mathrm{~mm}$ (2 cell and $24 \mathrm{hpf}), 0.1 \mathrm{~mm}$ (5 dpf).

E-F) Representative confocal image of $90 \%$ epiboly embryo co-injected at the 1-cell stage with mRNA encoding either C-terminal tagged Dmist-GFP (E, green) or DmistA22W-GFP (F, green) and membrane-RFP (magenta). Scale bar $=25 \mu \mathrm{m}$. 
1012

1013

1014

1015

1016

1017

1018

1019

1020

1021

1022

1023

1024

1025

1026

1027

1028

1029

1030

1031

1032

1033

1034

1035

Figure 3. CRISPR-generated dmist mutants sleep less and are hyperactive at night.

A) CRISPR/Cas9 targeting of the first exon in dmist resulted in an 8bp insertion (dmisti $)$ (grey line) within the coding sequence leading to an early stop codon (red line with *).

B) Predicted Dmisti8 peptide sequence lacks most of the $\mathrm{N}$-terminal signal peptide sequence (magenta) and the full C-terminus.

C-D) Representative $48 \mathrm{hr}$ traces of sleep (C) and waking activity (D) for dmisti8/i8 fish compared to $\mathrm{dmist}^{\mathrm{i} / /+}$ and $\mathrm{dmist}^{+/+}$siblings shows decreased sleep and increased waking activity at night. Mean \pm SEM is shown. $n=$ number of animals.

E-H) Analysis of sleep/wake architecture of the experiment depicted in (C, D) indicates that dmistisis larvae sleep less at night (E) due to fewer sleep bouts (F). Sleep bout length is unchanged (G). Waking activity was also increased in dmisti8/8 fish $(\mathrm{H})$. The black line represents the mean \pm SEM except for $G$, which is the median. ${ }^{*} p<0.05,{ }^{* *} p<0.01$, ${ }^{* * *} \mathrm{p}<0.001$; One-way ANOVA, Tukey's post hoc test.

I) Combining 5 independent experiments with a linear mixed effects model reveals $d m i s t^{i 8 / i 8}$ fish sleep less due to fewer sleep bouts, and also show increased waking activity at night. Plotted are the genotype effect sizes (95\% confidence interval) on each parameter relative to wild type. Shading indicates day (white) and night (grey). P-values are assigned by an F-test on the fixed effects coefficients from the linear mixed effects model. ${ }^{*} p<0.05$, ${ }^{* *} p<0.01,{ }^{* *} p<0.001, n s p>0.05$

J) $d m i s t^{i 8 / 8}$ larvae have increased rebound sleep compared to wild type siblings following exposure to $5 \mathrm{mM}$ PTZ. Representative sleep traces of $d \mathrm{mist}^{+/+}$(no drug, water vehicle controls in black; PTZ exposed in blue) and dmisti8/i8 (no drug in purple; PTZ exposed in red) following $1 \mathrm{hr}$ exposure to $5 \mathrm{mM} \mathrm{PTZ} \mathrm{(black} \mathrm{bar)} \mathrm{in} \mathrm{the} \mathrm{morning.} \mathrm{Data} \mathrm{are} \mathrm{mean} \pm$ SEM. $d m i s t^{i 8 /+}$ animals are not plotted for clarity but are included in panel $\mathrm{K}$. 
K) Rebound sleep after exposure to 5mM PTZ, calculated from the experiment in J. Each dot represents a single larva, grey lines show mean \pm SEM. As shown in Figure S4C, normalizing the PTZ responses to the mean control baselines for each genotype shows that $d m i s t^{i 8 / i 8}$ fish have a significantly increased response relative to their sibling controls. $1040 \quad(p<0.05$, one-way ANOVA $)$. L-M) Adult $d m i s t^{i 8 / i 8}$ fish are more active at night. 48-hour centroid tracking shows $d m i s t^{i 8 / i 8}$ adults have a higher mean swim speed compared to their wild type siblings (L). Mean speed at night is quantified in $M$ (cross shows mean \pm SEM). ${ }^{*} p<0.05$, one-way ANOVA. 
Figure 4. Mutation of the dmist related gene fxyd1 causes reduced sleep at night.

A) Schematic of zebrafish Dmist and Fxyd1 protein domains and alignments comparing human, mouse, and zebrafish Dmist and FXYD1 protein sequences. Black and grey shading indicate amino acid identity and similarity, respectively. The FXYD domain is highlighted with a red line and the RRR motif in the C-terminus is indicated with a blue line.

B) CRISPR-Cas9 targeting of the $3^{\text {rd }}$ exon of $f x y d 1$ created a 28 bp deletion predicted to encode a truncated protein. The start codon is marked by a blue line. Guide RNA target sequence and PAM sequence are shown as grey bars.

C) In situ hybridisation of fxyd1 at $24 \mathrm{hpf}$ (whole animal) and $5 \mathrm{dpf}$ brain (ventral view). Anterior is to the left. Scale bar $=0.5 \mathrm{~mm}(24 \mathrm{hpf}) ; 0.1 \mathrm{~mm}(5 \mathrm{dpf})$.

D-E) Representative single tracking experiment showing $f x y d 1^{\Delta 28}$ mutants have decreased night-time sleep (D) but normal waking activity (E).

F) Combining 5 independent experiments with a linear mixed effects model reveals $f x y d 1^{\Delta 28 /}$ $\Delta 28$ larvae sleep significantly less at night due to a shorter sleep bout length compared to fxyd1+t+ siblings. Plotted are the genotype effect sizes (95\% confidence interval) on each parameter relative to wild type. Shading indicates day (white) and night (grey). P-values are assigned by an F-test on the fixed effects coefficients from the linear mixed effects model. ${ }^{*} \mathrm{p}<0.05,{ }^{* *} \mathrm{p}<0.01,{ }^{* * *} \mathrm{p}<0.001, \mathrm{~ns} \mathrm{p}>0.05$ 
1065

\section{Figure 5. Mutations in the $\mathrm{Na}+\mathrm{K}+$ pump alpha subunit atp1a3a reduces sleep at night}

A) CRISPR-Cas9 targeting of the atp1a3a resulted in a 19 bp deletion that eliminates the start codon (blue) and splice junction.

B) CRISPR-Cas9 targeting of atp1a3b resulted in a $14 \mathrm{bp}$ deletion that eliminates the start codon (blue)..

C) In situ hybridisation of atp1a3a and atp1a3b at 24hpf (whole animal) and 5dpf brain (ventral view). Anterior is to the left. Scale bar $=0.5 \mathrm{~mm}(24 \mathrm{hpf}) ; 0.1 \mathrm{~mm}(5 \mathrm{dpf})$.

D) Representative single tracking experiment showing atp $1 a 3 a^{\Delta 19 / \Delta 19}$ fish are hyperactive throughout the day-night cycle and have decreased sleep at night.

E) Representative single tracking experiment showing atp1a3b $b^{\Delta 14 / \Delta 14}$ mutants have increased daytime waking activity but normal sleep patterns.

F) atp 1a3a ${ }^{\Delta 19 / \Delta 19}$ larvae sleep less at night due to shorter sleep bouts. Plotted are the genotype effect sizes (95\% confidence interval) on each parameter relative to wild type. Shading indicates day (white) and night (grey). P-values are assigned by an F-test on the fixed effects coefficients from the linear mixed effects model. ${ }^{*} p<0.05,{ }^{* *} p<0.01,{ }^{* * *} p<0.001$, ns $p>0.05$

G) Brain sodium levels are significantly elevated after exposure to PTZ in both $\operatorname{atp} 1 a 3 a^{\Delta 19 / \Delta 19}(\mathrm{~N}=2)$ and $d m i s t^{i 8 / i 8}(\mathrm{~N}=4)$ fish relative to wild type and heterozygous mutant siblings, as measured by fluorescence intensity of Sodium Green, normalized to the sample mean intensity. Crosses show mean \pm SEM. ${ }^{*} p<0.05,{ }^{* *} p<0.01$, one-way ANOVA H) Under baseline conditions, brain sodium levels are significantly elevated in $d m i s t^{i 8 / i 8}$ fish at night but not during the day, as measured by fluorescence intensity with Sodium Green. Crosses show mean \pm SEM. ${ }^{*} \mathrm{p}<0.05,{ }^{* *} \mathrm{p}<0.01$, one-way ANOVA 
Figure S1. A viral insertion screen for sleep-wake regulators

A) Schematic of screening strategy. Candidate genes were selected from a list of 904 mammalian genes encoding protein classes most often linked to behavioural regulation, including 1) genes previously implicated in sleep and circadian rhythms; 2) G-protein coupled receptors; 3) neuropeptide ligands; 4) channels; and 5) proteins involved in posttranslational regulation, such as de-ubiquitinating enzymes (Supplemental Data 1). tBLASTN of the human protein sequences identified 1162 zebrafish orthologs (Zv6), of which $702(60.4 \%)$ had viral inserts mapped in the 'Zenemark' zebrafish viral insertion library (Varshney et al., 2013). Sperm harbouring viral insertions in 25 loci were successfully used for in vitro fertilization and propagated to the F3 generation for screening. F3 larvae from single family F2 in-crosses were monitored on a 14hr:10hr light:dark cycle from 4-7dpf using videography and genotyped at the end of the experiment. normalized as standard deviations from mean (Z-score) of all the viral-insertion lines tested (including heterozygous vir/+ and homozygous vir/vir). Line 10543 (renamed dreammist) exhibited decreased daytime sleep and increased daytime activity. 
Figure S2. dmist $^{\text {vir/vir }}$ fish are hyperactive and have normal circadian rhythms.

A) Free-running circadian period length of locomotor activity of fish that were entrained until for 48 hours after the shift to darkness, shows no difference between dmistvir/vir larvae and their sibling controls. $p>0.05$, one-way ANOVA B-C) Representative 48hr sleep (B) and waking activity (C) traces of progeny from dmistvir/+ in-cross following the transition from a 14hr:10hr light:dark cycle to constant dark conditions. Light and dark grey blocks show subjective day and night, respectively. Data are mean \pm SEM.

D) Quantitative RT-PCR time-course before (light) and after (grey) transfer into constant dark demonstrates that dmist mRNA levels do not oscillate with a circadian period, unlike per1 mRNA which does. $\mathrm{n}=3$ replicates per timepoint. Expression is normalized to circadian time 3. Data are mean \pm SEM. 
1121

Figure S3. dmist is enriched in neurons and requires the signal peptide cleavage site for membrane localisation.

A) Relative expression level of dmist transcript from RNA sequencing of $6 \mathrm{dpf} d m i s t^{\text {virvir }}$ and dmist ${ }^{++}$siblings. Z-score calculated by subtracting mean expression and normalising by the standard deviation across all expressed transcripts (27,243 transcripts). Data show mean \pm SEM from 3 independent biological replicates. ${ }^{* *} p<0.01$ Student's t-test.

B) 3' and 5' RACE identify a long (1100bp) and short (215bp) 3'UTR variant in dmist_Dr, and a long 3'UTR (1050bp) in Dmist_Mm. The purple arrow indicates the ISH probe used in Figure 2D.

C) dmist_Dr sense probe at $24 \mathrm{hpf}$ shows no detectable expression.

D) Percentage identity matrix comparing Dmist homologues across 6 vertebrate species $(100 \%=$ magenta; $>70 \%=$ purple; $>50 \%=$ cyan; $<50 \%=$ green $)$.

E) Hierarchical clustering of RNAseq dataset of 6 different cell types isolated from the developing (E13.5) mouse brain (Zhang et al., 2014) and post-hoc identification of Dmist_Mm. Data standardized by subtracting the mean expression and normalizing by the standard deviation across all expressed transcripts in each cell type (column). Dmist_Mm (green arrow) co-clusters with genes highly expressed in neurons (green shaded branches).

F) Pearson rank correlation of canonical cell-type markers with Dmist_Mm shows high coexpression with neuronal markers compared to astroglial markers. Data are mean \pm SEM ${ }^{*} \mathrm{p}<0.05,{ }^{* *} \mathrm{p}<0.01 ;$ Kruskal-Wallis, Dunn-Sidak post-hoc test.

G-I) Predicted processing of Dmist to its mature form in the plasma membrane (G) and Cterminal GFP fusion to Dmist is predicted to localise to the membrane $(\mathrm{H})$ The black triangle represents the cap. However, a mutation (A22W) at the signal peptide cleavage site (I) is 
bioRxiv preprint doi: https://doi.org/10.1101/2020.11.18.388736; this version posted December 6,2020 . The copyright holder for this preprint (which was not certified by peer review) is the author/funder, who has granted bioRxiv a license to display the preprint in perpetuity. It is made available under aCC-BY 4.0 International license. of the mature protein. 
Figure S4. CRISPR-generated dmist mutants have altered sleep and arousal phenotypes

A) Quantitative RT-PCR shows dmistis/i8 larvae have reduced dmist mRNA levels, suggesting that $d m i s t^{i 8}$ transcripts undergo nonsense mediated decay. Data are mean \pm SD of three biological replicates. ${ }^{* *} p<0.01$; one-way ANOVA, Tukey's post-hoc test.

B) Relative expression level of dmist transcript from RNA sequencing of $6 \mathrm{dpf} d m i s t^{i 8 / i 8}$ and dmist $^{+/+}$siblings. Z-score calculated by subtracting mean expression and normalising by the standard deviation across all expressed transcripts. Data are mean \pm SEM for 3 independent biological replicates. ${ }^{* *} p<0.01$, Student's t-test.

C) Effect size of change in sleep after 1 hour 5mM PTZ treatment (and washout) compared to vehicle treated controls (error bars show $95 \%$ confidence intervals). ${ }^{*} p<0.05$, one-way ANOVA.

D) Cumulative probability distribution of the all night-time swimming speeds in representative adult tracking experiment. The dashed lines show the half max $(0.5$ probability) for each curve. $n$ indicates number of fish. ${ }^{*} p<0.05$; Kolmogorov-Smirnov test. 
bioRxiv preprint doi: https://doi.org/10.1101/2020.11.18.388736; this version posted December 6, 2020. The copyright holder for this

A) preprint (which was not certified by peer review) is the author/fun Bis), who has granted bioRxiv a license to display the preprint in
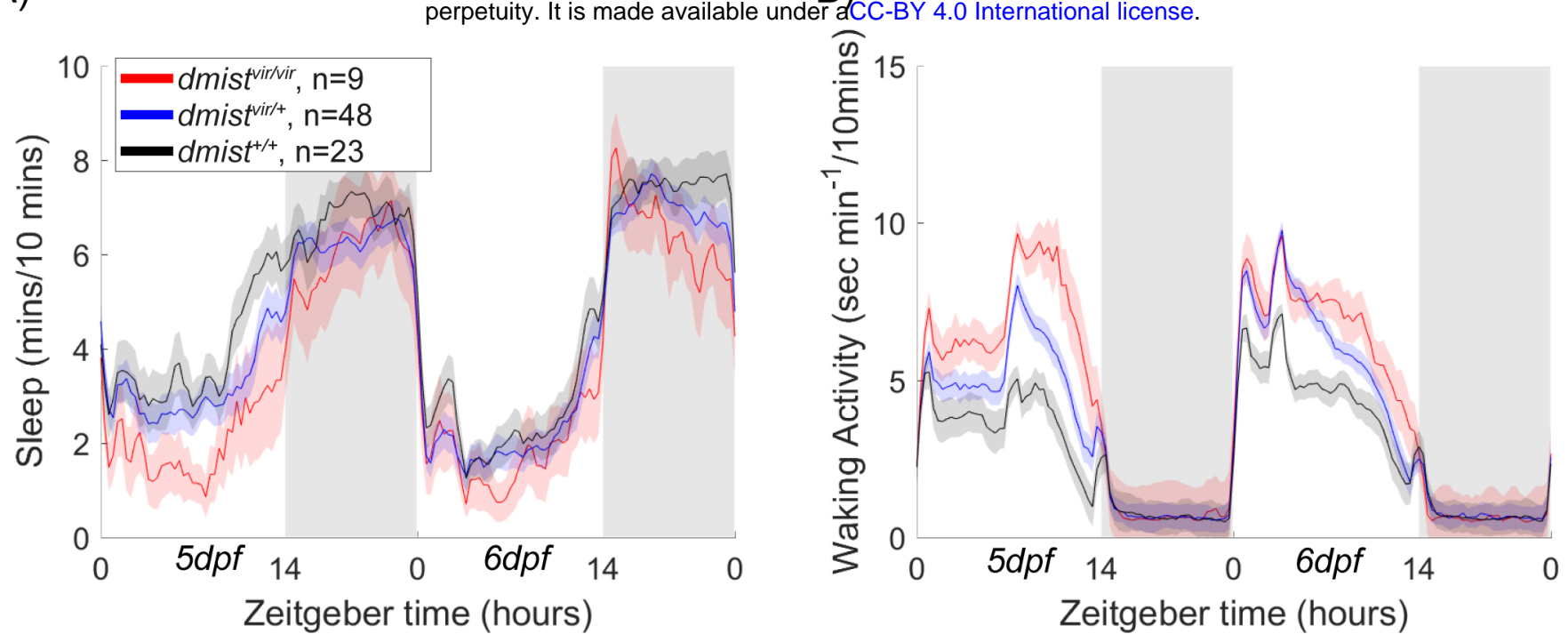

C)

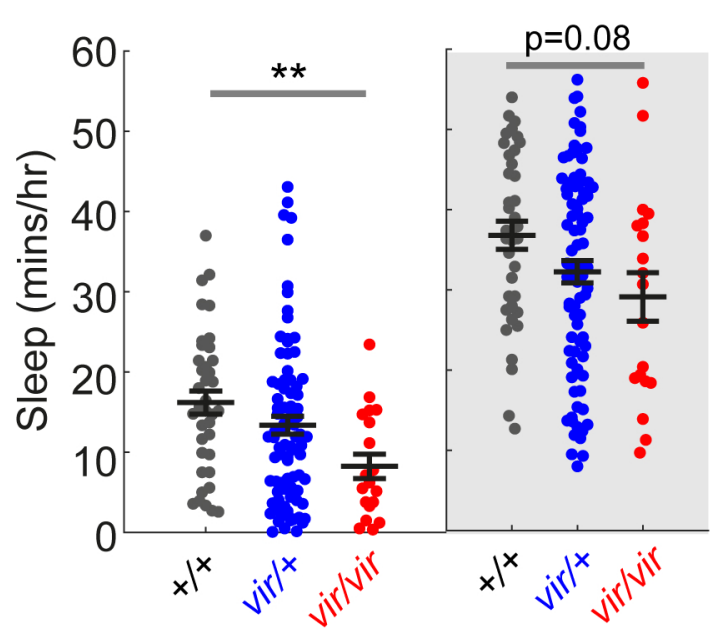

E)

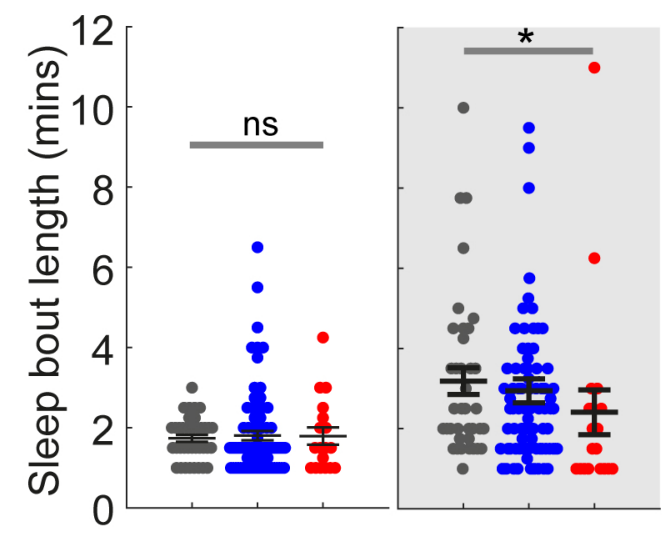

F)
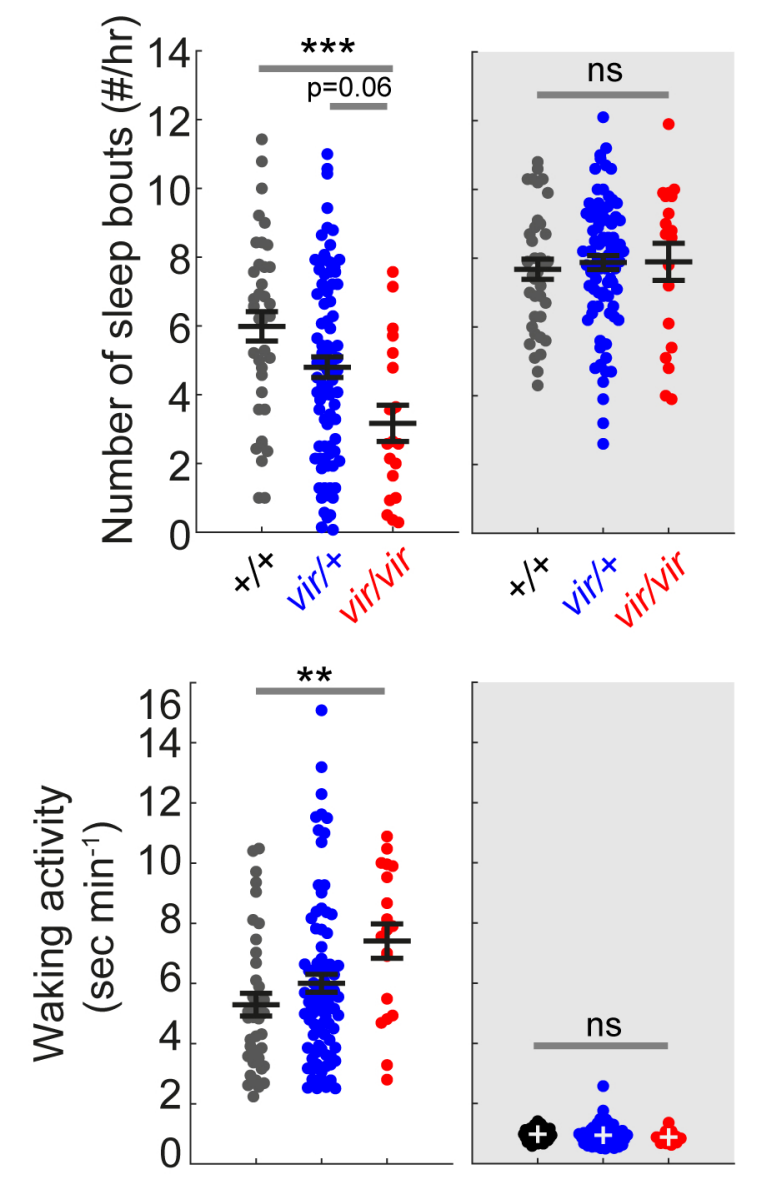

$\begin{array}{lllllllll}\text { G) } \quad+\text { + vs vir/vir } & * * * & * * * & * * * & * & * & * * * & * * & \mathrm{~ns} \\ \text { vir/+ vs vir/vir } & * * & * & \mathrm{~ns} & \mathrm{~ns} & \mathrm{~ns} & * & * * & \mathrm{~ns}\end{array}$

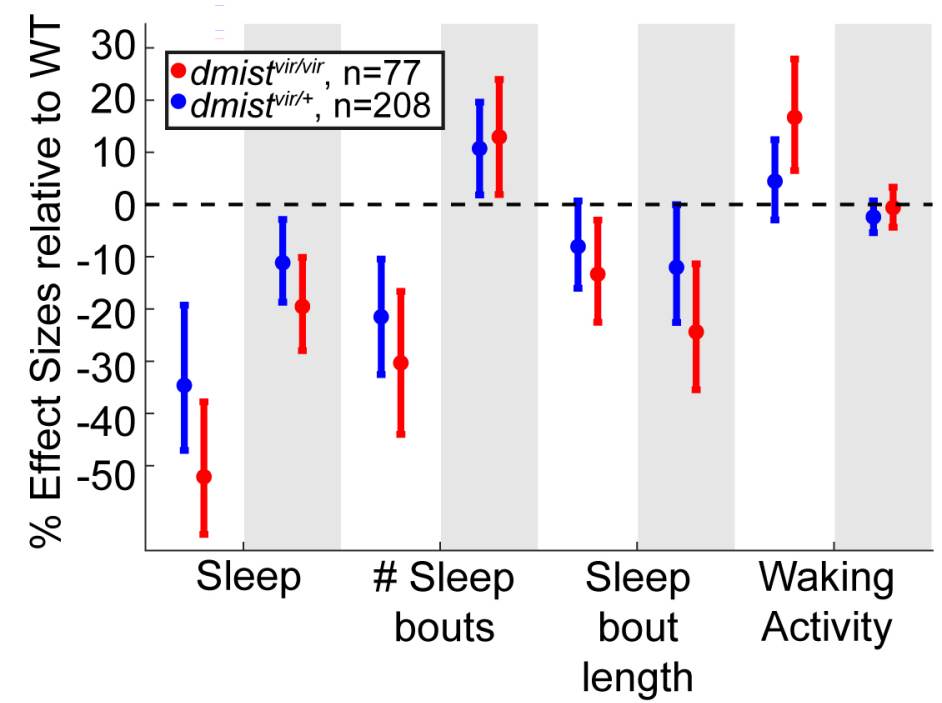


A) bioRxiv preprint doi: https://doi.org/10.1101/2020.11.18.388736; this version posted December 6,2039 The copyright holder for thi
preprint (which was not certified by peer review) is the author/funder, who has granted bioRxiv a lisendse to display the preprint in
perpetuity. It is/made apratuabletunder aCC-BY 4.0 International license.

A) bioRxiv preprint doi: https://doi.org/10.1101/2020.11.18.388736; this version posted December 6, $29 \beta_{0}$
preprint (which was not certified by peer review) is the author/funder, who has granted bioRxiv a liser
perpetuity. It is/made apratuabletunder aCC-BY 4.0 International license.
Mus musculus Chr5

Homo sapiens Chr12

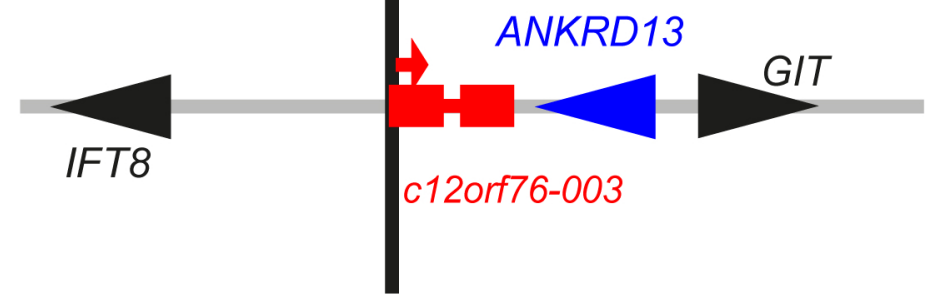

RIKEN cDNA 1500011B03-001

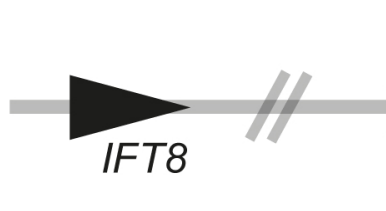

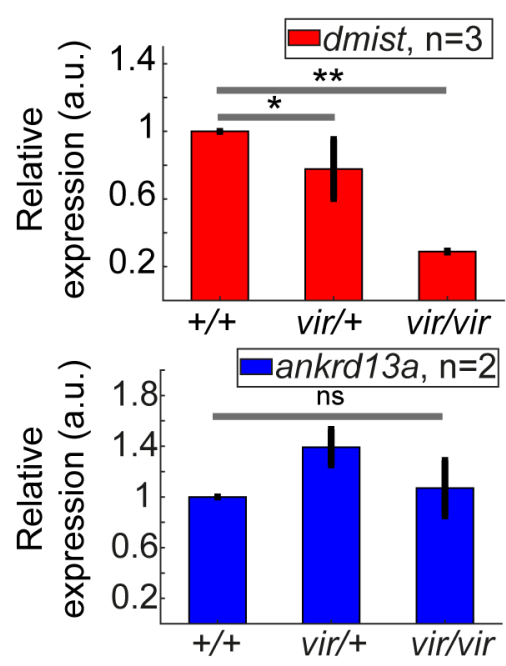

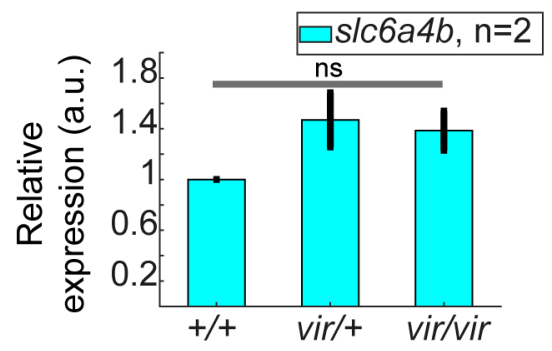

C)
Predicted Signal Peptide

Danio rerio Takifugu rupribes Tetraodon nigroviridis

Xenopus laevis

Mus musculus

Homo sapiens Gallus gallus
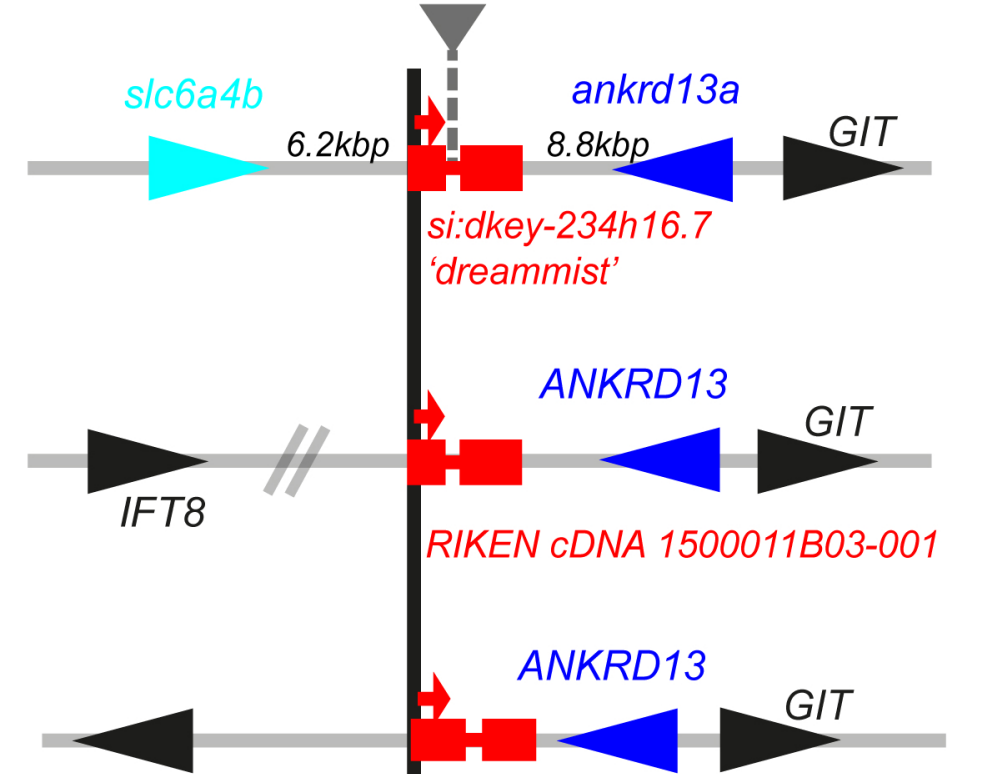

.
ANKRD13 Chr5

D)

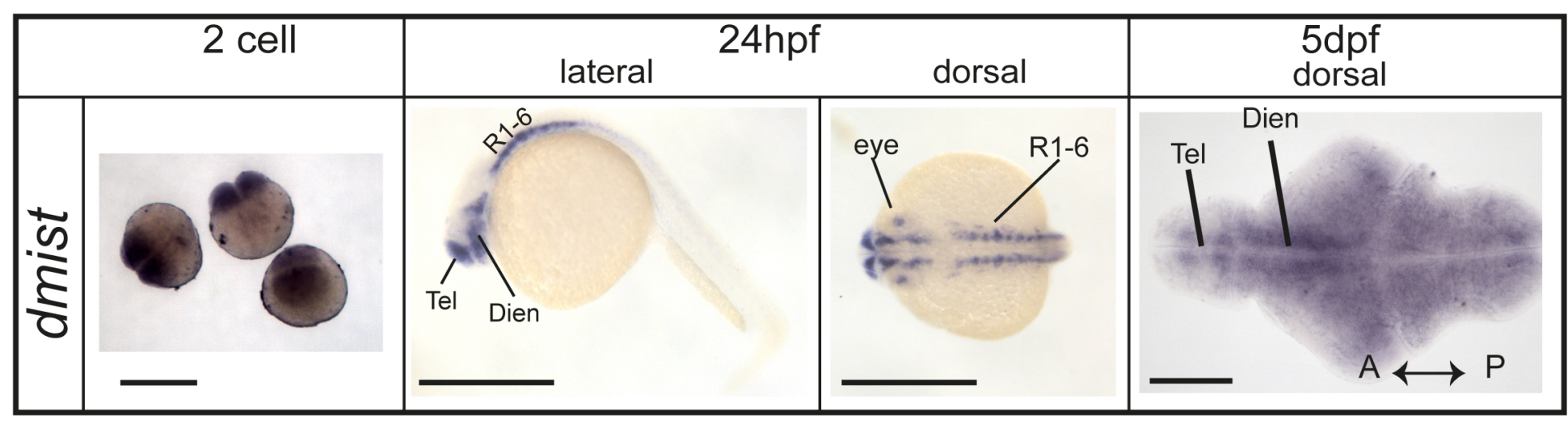

E)
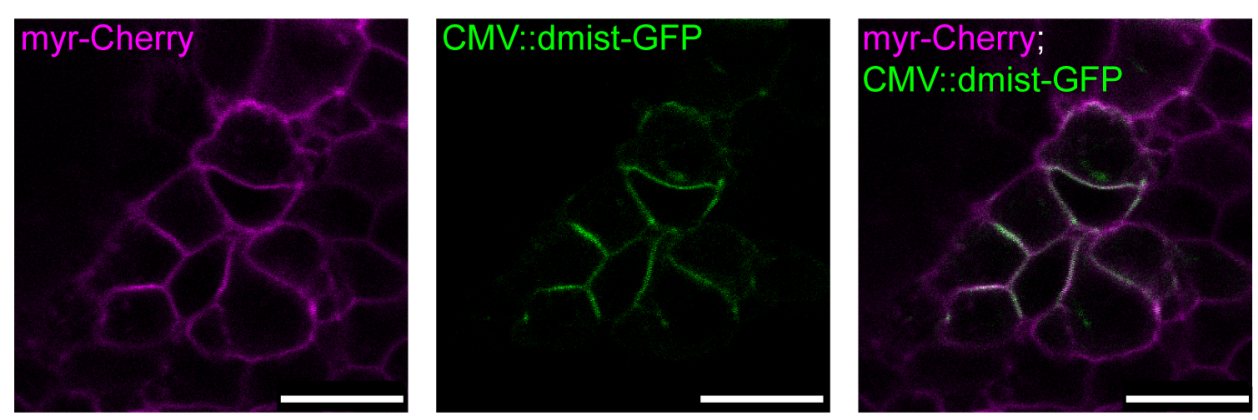

F)

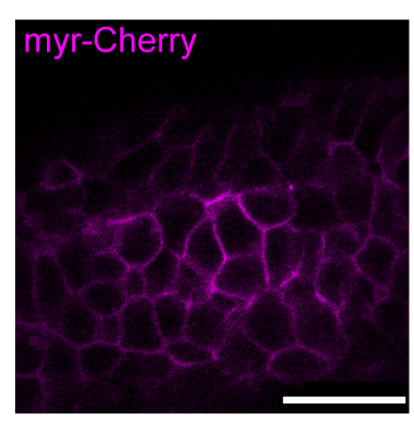

Predicted Transmembrane

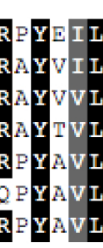

RQNLVI I S SVITLLIF MIGMA

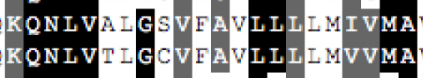

KQNLVIIGSIICILFIAMILIA

RQNLV I GSI ISALLITIVIMA RQSLVIMATIF ILIVTVLLMA QN LV LMGTIF I L LVTVI LMA
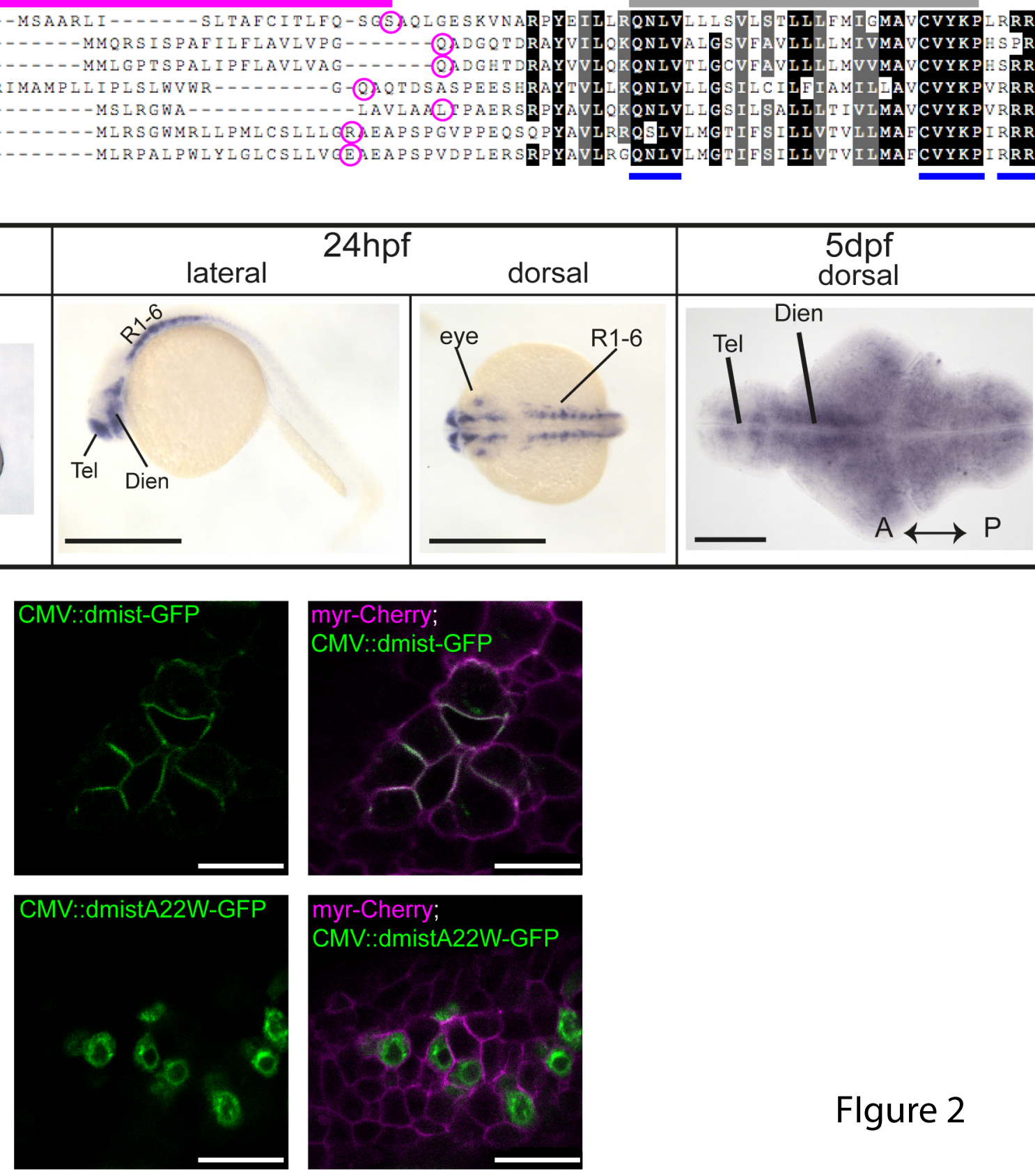


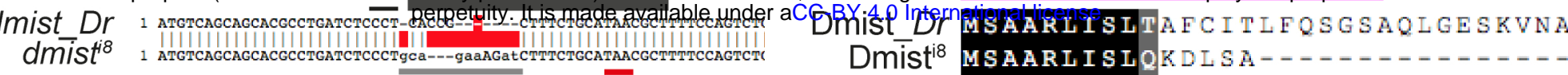

Dmist $^{18}$ MSAARL I SLQKDLSA $\ldots$

C)

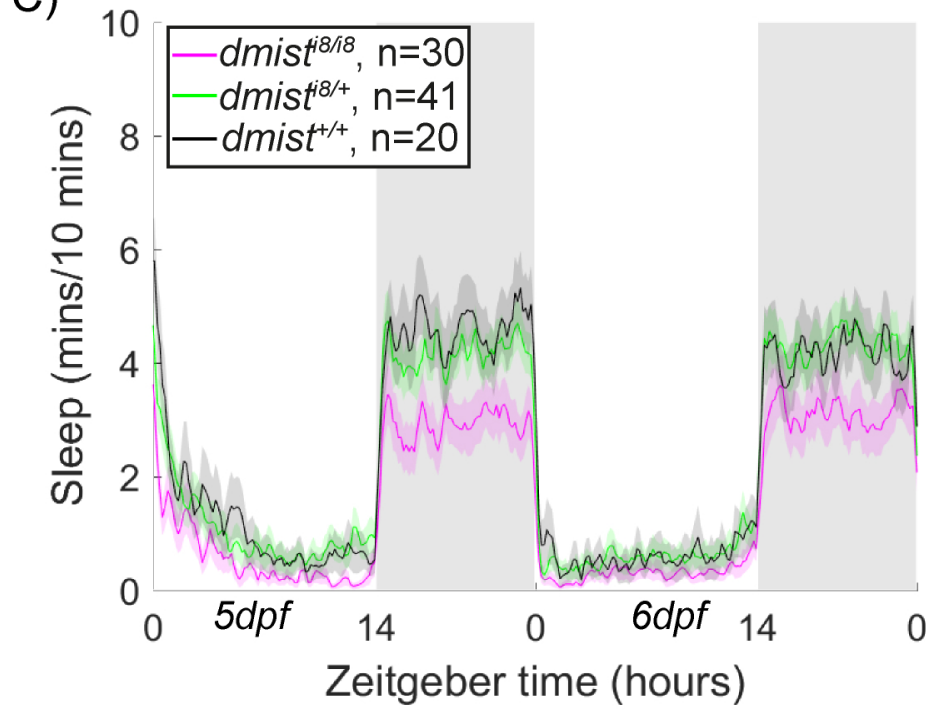

E)

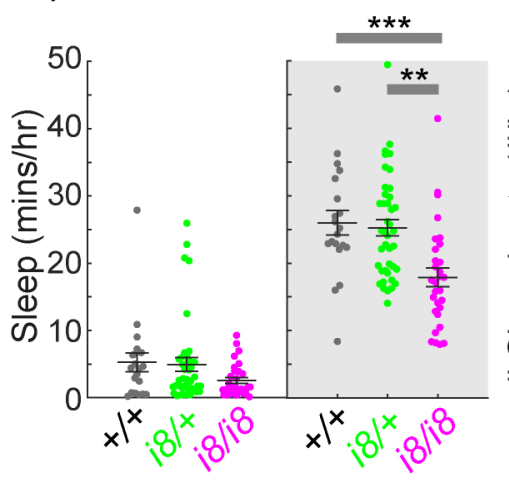

F)

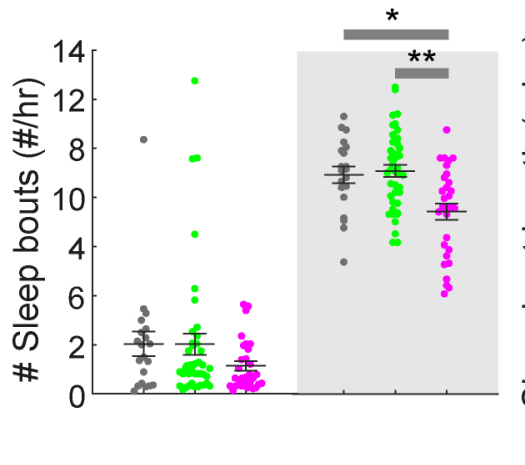

D)

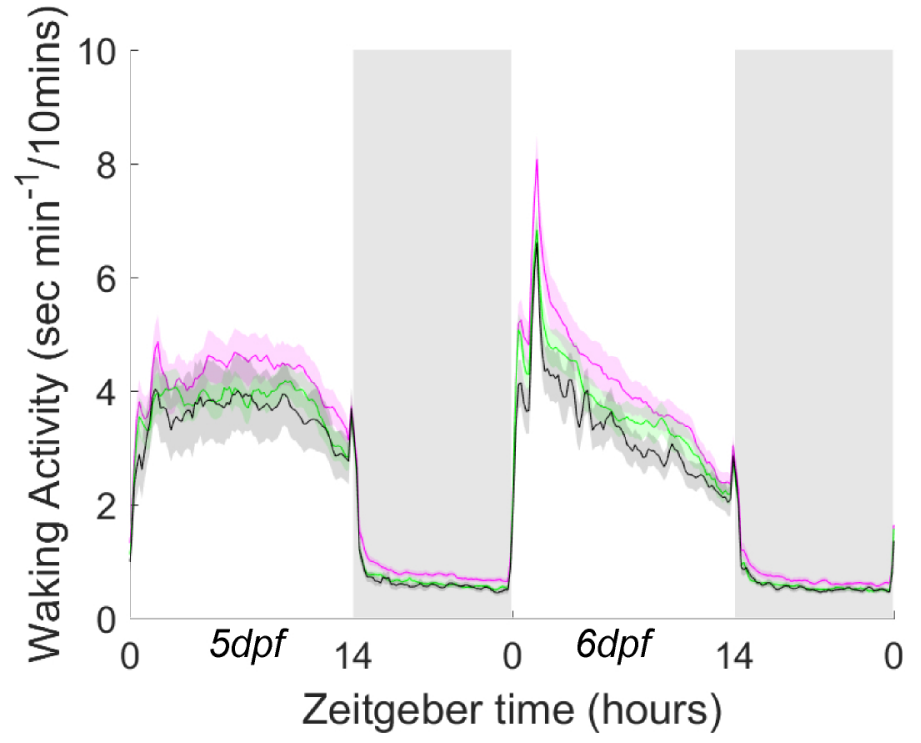

G)

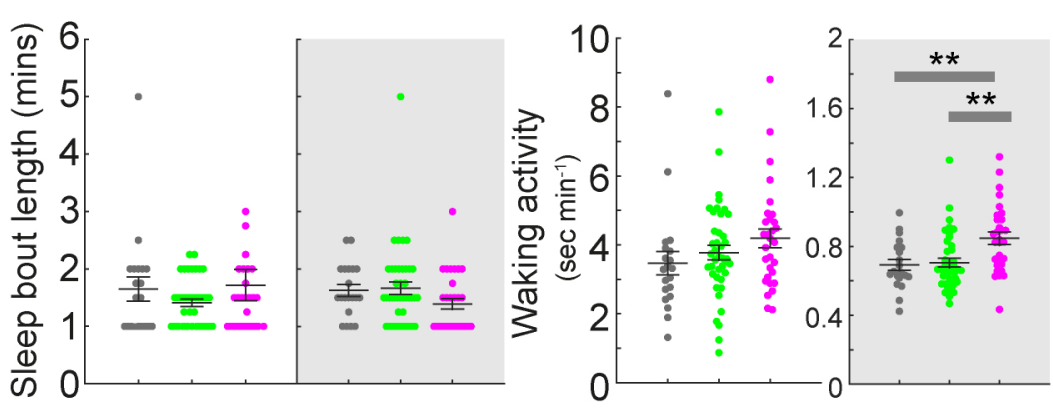

l) +

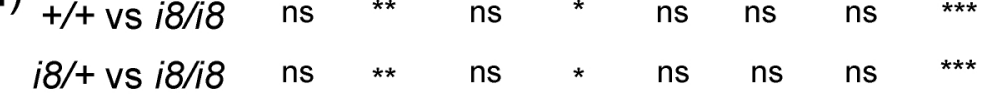

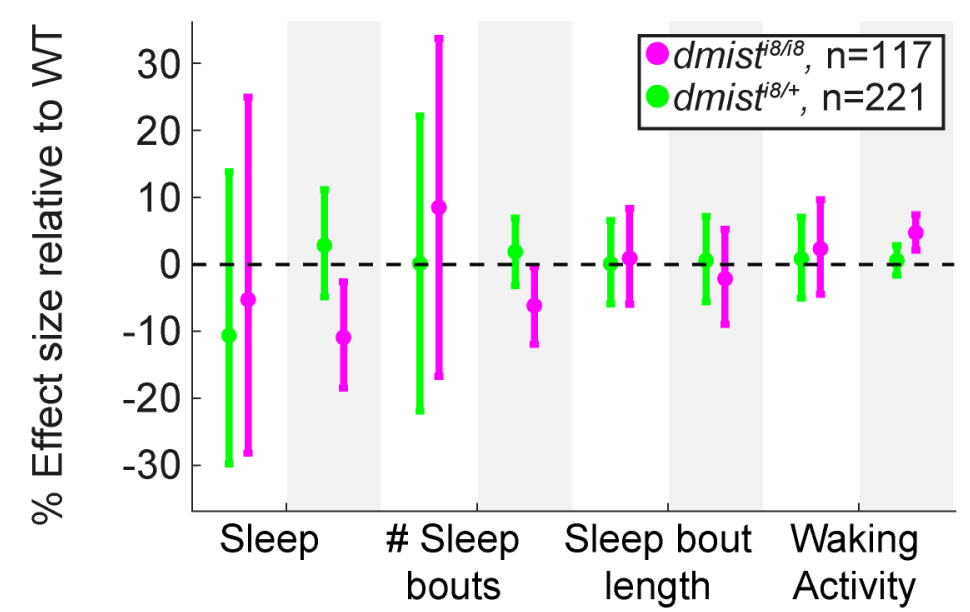

K)

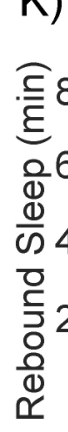

L)

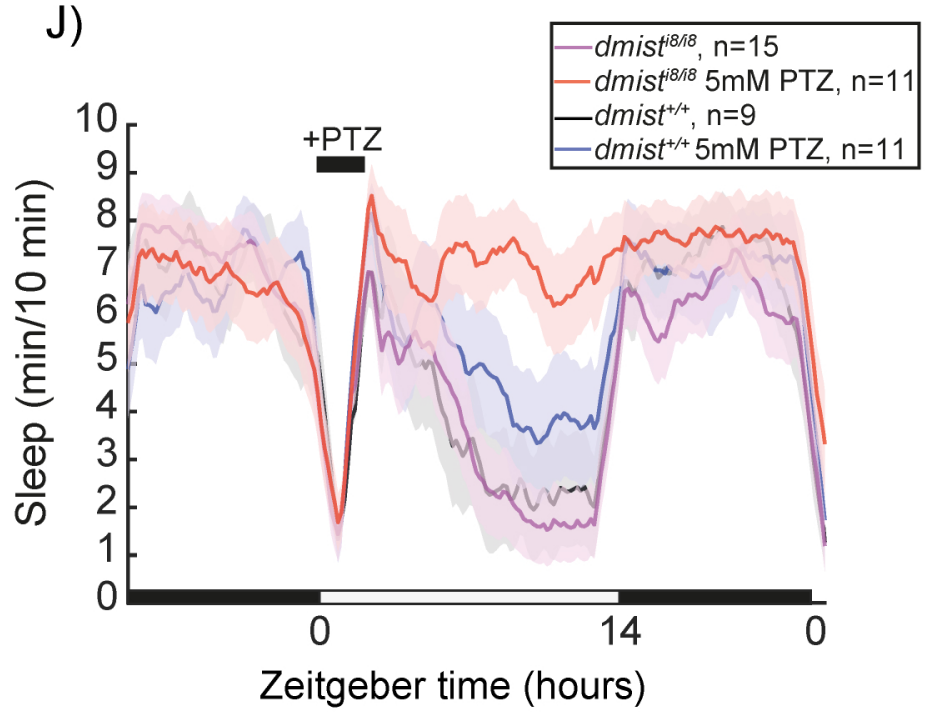

M) 
B)

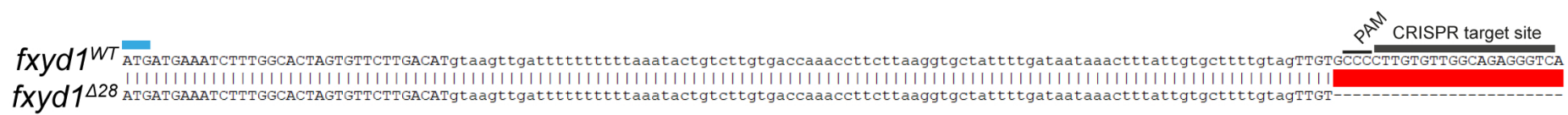

GCAGACCAgtaagtcttctcaatttcttttatttatgtgtagtgataaaaaatgttaaattaaaattaaatgtttttttttgcettgcattttgcagCAGAGGATGATCCCTTCTCTTTTGgtaagtttttttttaaatatttaaata IIIIII11111111111111111111111111111111111111111111111111111111111111111111111111111111111111111111111111111111111111111111111111111111111111

Fxyd 1 WT MMKS LALVFLTFVPLVLAEGQQTTED
Fxyd1 1228 MMKS LALVFLTFVPRMIPSLIIITD

C)

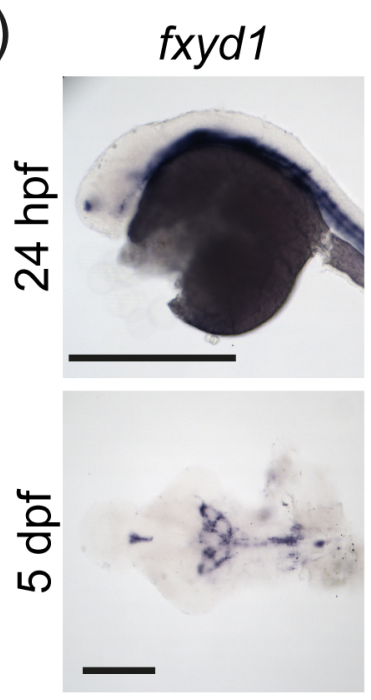

D)

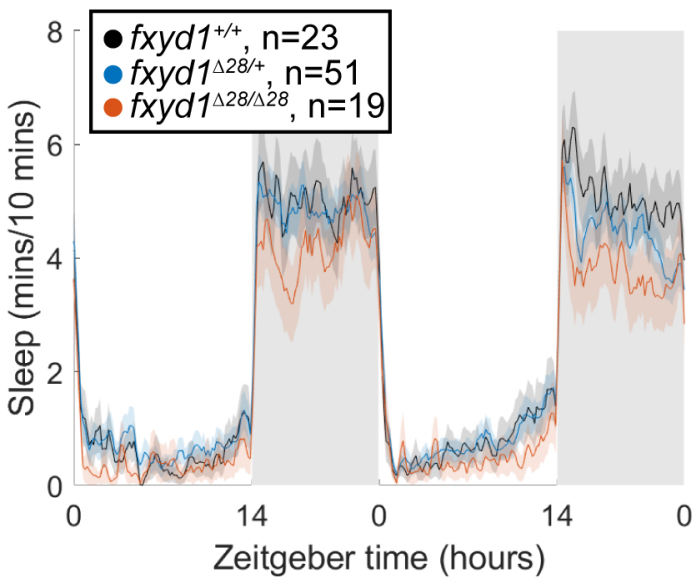

E)

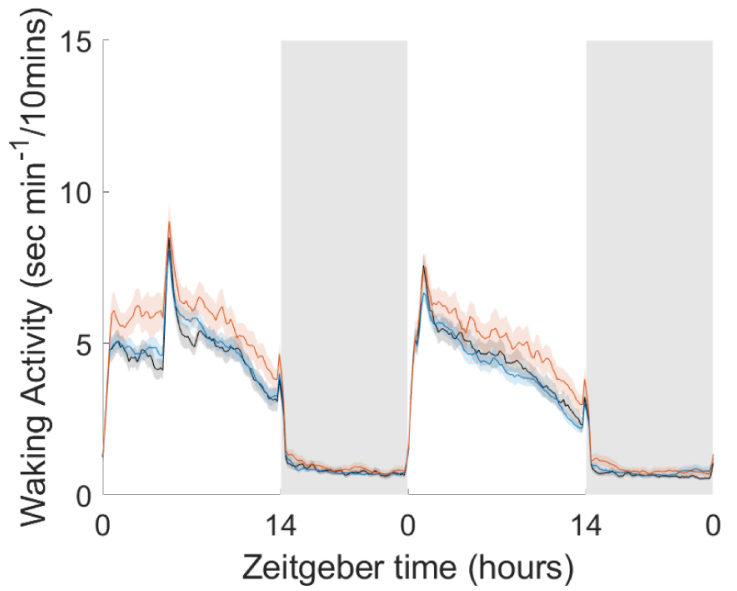

$\begin{array}{rllllllll}+/+ \text { vs } \Delta 28 / \Delta 28 & n s & * * & n s & n s & n s & * * * & n s & n s \\ \Delta 28 /+ \text { vs } \Delta 28 / \Delta 28 & n s & * & n s & * & n s & * * & n s & n s\end{array}$

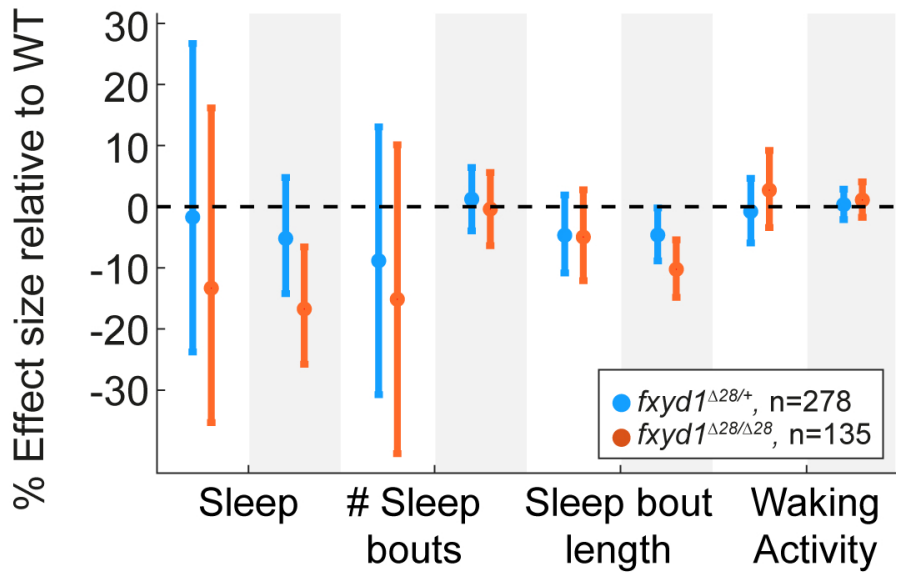


A)

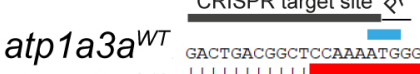

atp1a3a 119 MACTGACGGCT

B) atp1a3 $b^{W T}$ CRISPR target site $P^{2}$

作 atp1a3b 14 C. $1111111111110-110-1111111111111111111111111111111111111111111111111111111111111111111111111111111111111111111111111$

C)

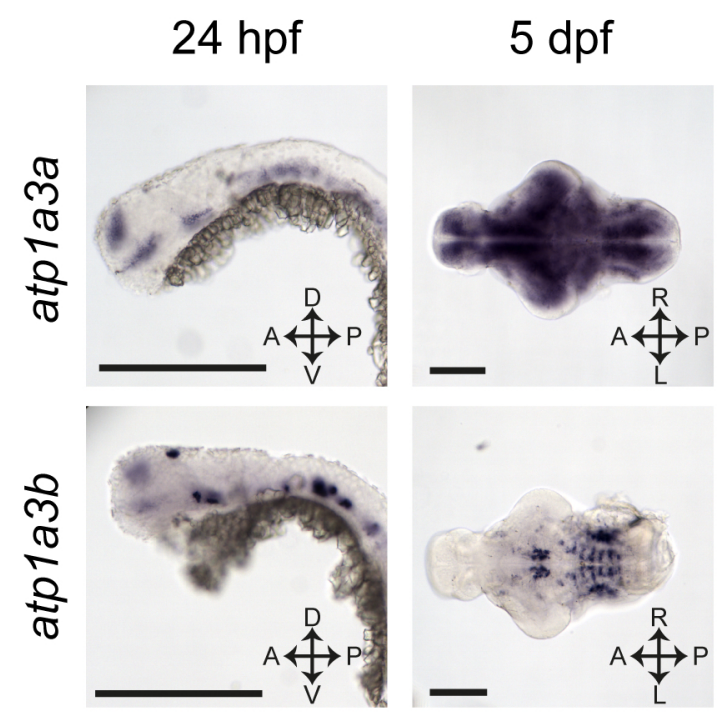

D)
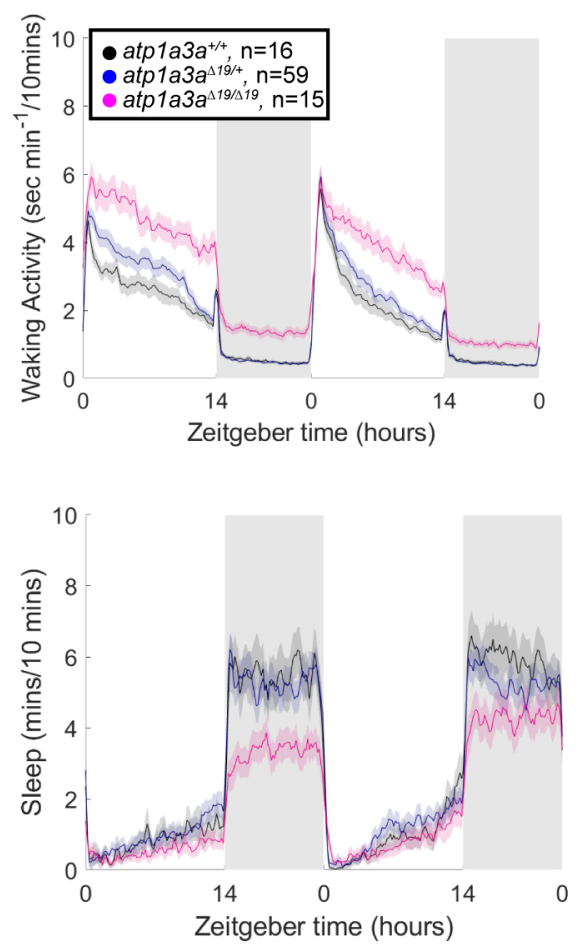

E)
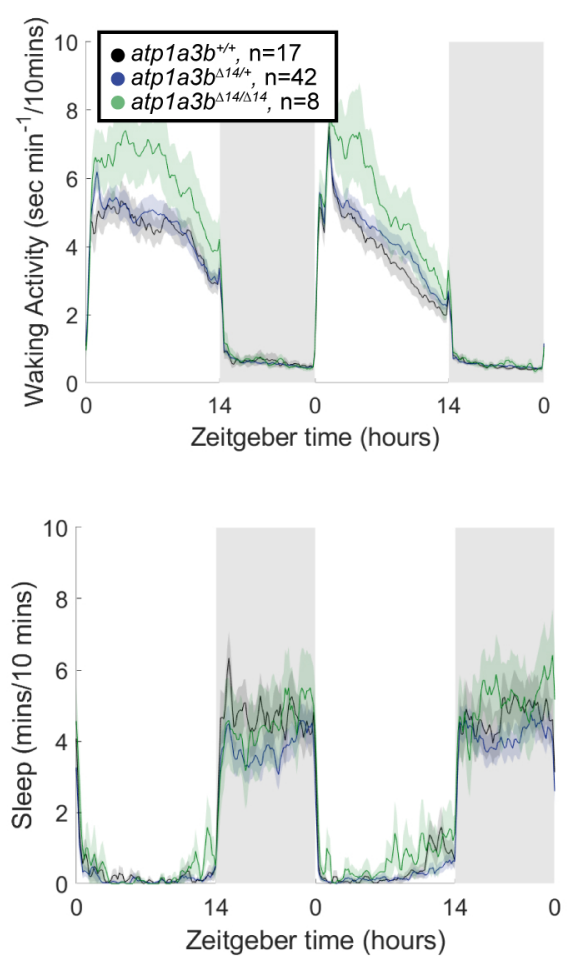

F)

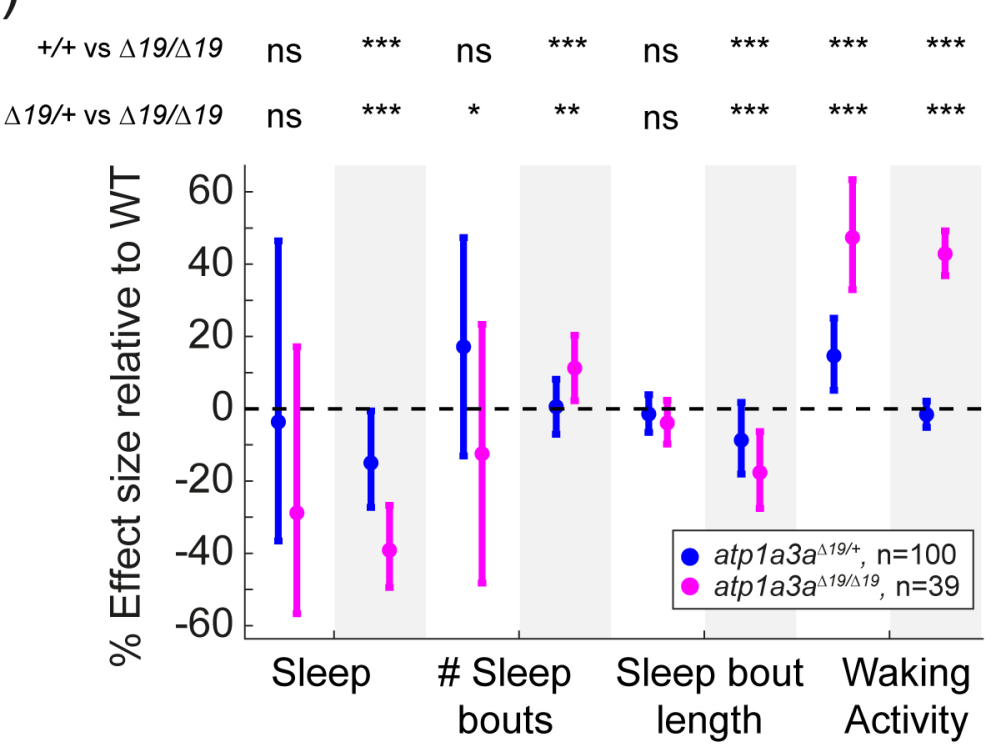

G)

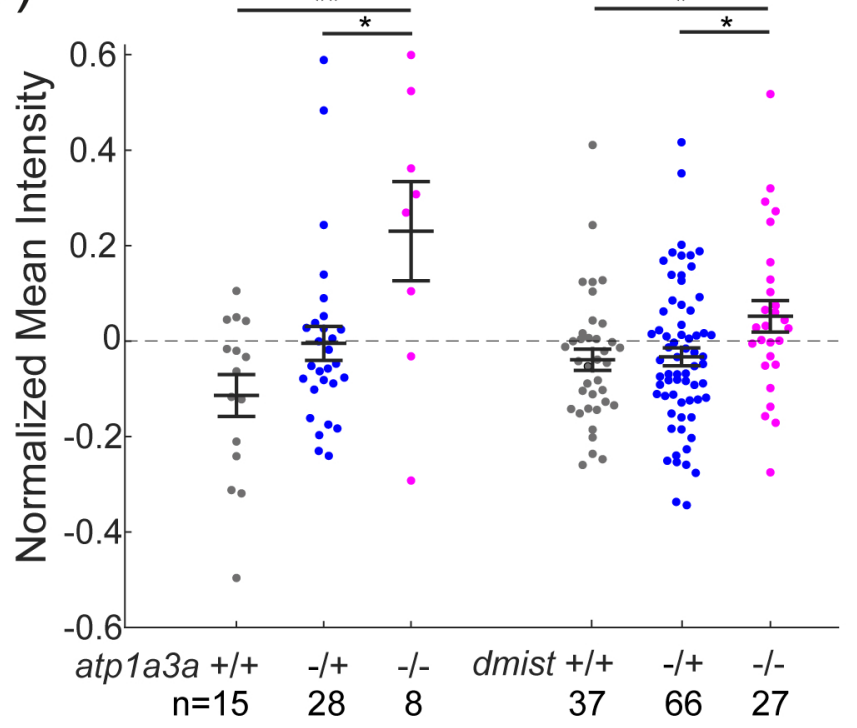

H)

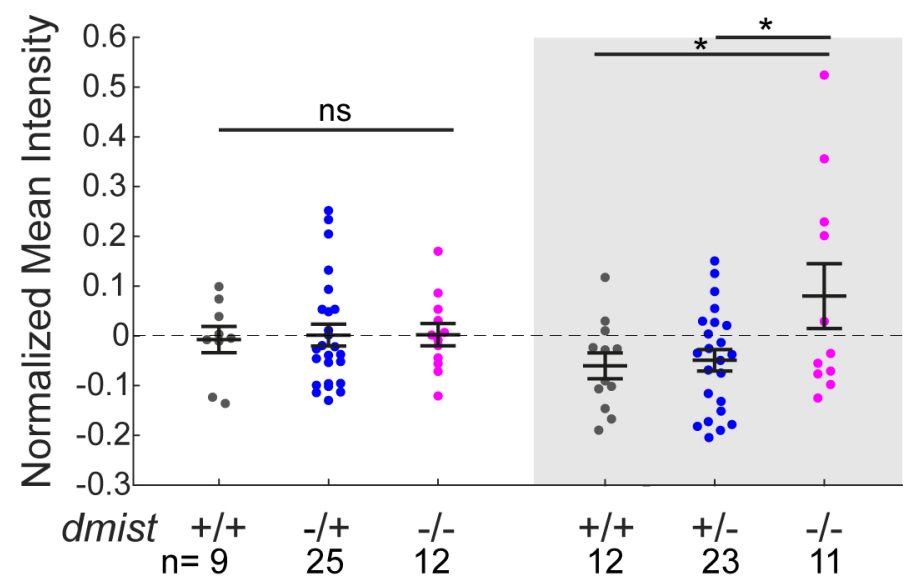


A) B)

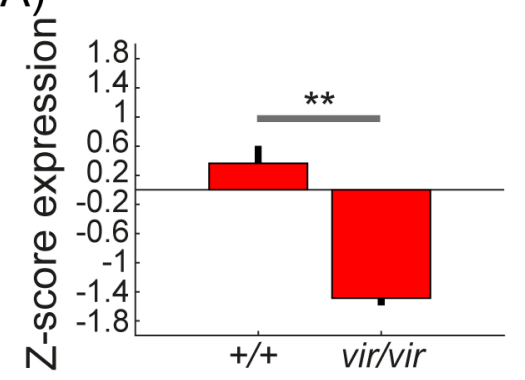

D)

\begin{tabular}{|l|r|r|r|r|r|r|}
\hline Species & $\begin{array}{l}\text { Danio } \\
\text { rerio }\end{array}$ & $\begin{array}{l}\text { Takifugu } \\
\text { rupibes }\end{array}$ & $\begin{array}{l}\text { Xenopus } \\
\text { laevis }\end{array}$ & $\begin{array}{l}\text { Gallus } \\
\text { gallus }\end{array}$ & $\begin{array}{l}\text { Mus } \\
\text { musculus }\end{array}$ & $\begin{array}{l}\text { Homo } \\
\text { sapiens }\end{array}$ \\
\hline Danio rerio & 100.00 & 56.82 & 52.08 & 61.36 & 43.75 & 47.92 \\
\hline Takifugu rupibes & 56.82 & 100.00 & 52.27 & 54.55 & 38.64 & 45.45 \\
\hline Xenopus laevis & 52.08 & 52.27 & 100.00 & 68.18 & 46.00 & 52.00 \\
\hline Gallus gallus & 61.36 & 54.55 & 68.18 & 100.00 & 65.91 & 72.73 \\
\hline Mus musculus & 43.75 & 38.64 & 46.00 & 65.91 & 100.00 & 84.31 \\
\hline Homo sapiens & 47.92 & 45.45 & 52.00 & 72.73 & 84.31 & 100.00 \\
\hline
\end{tabular}

E)

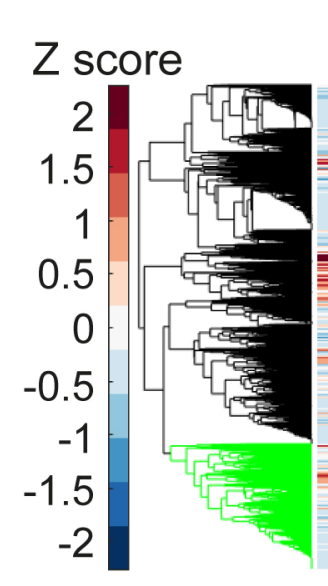

G)

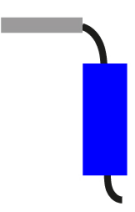

Pre-Dmist

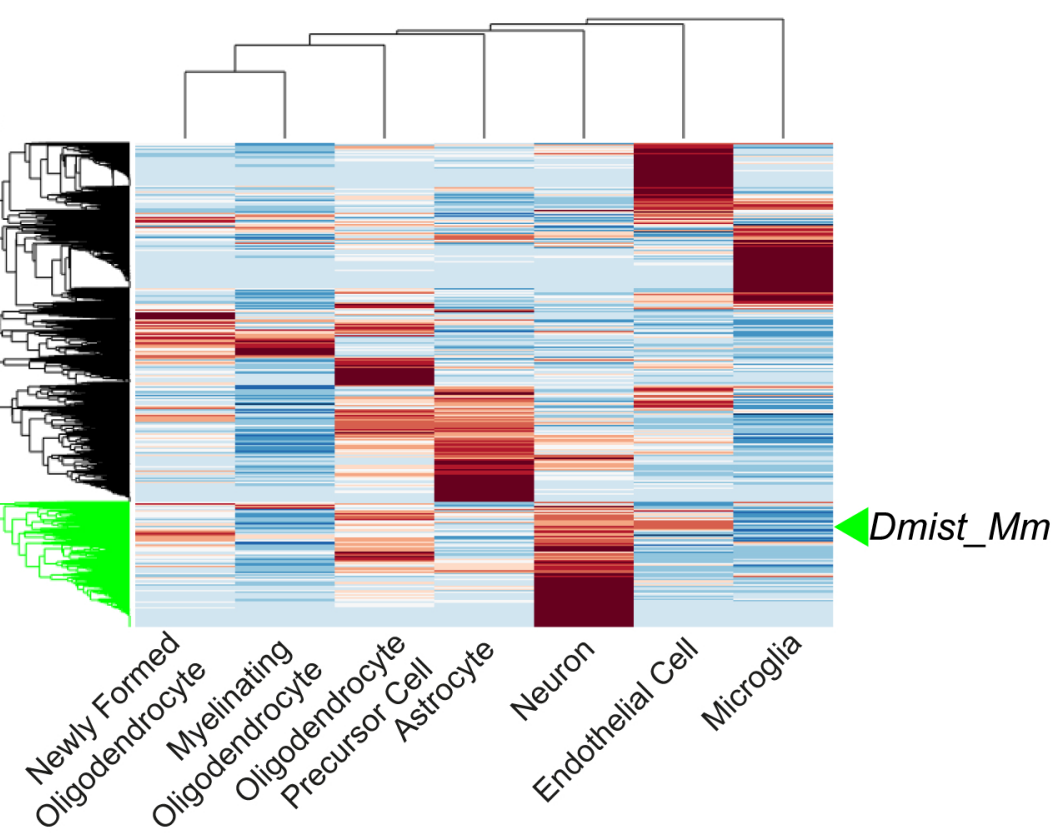

F)

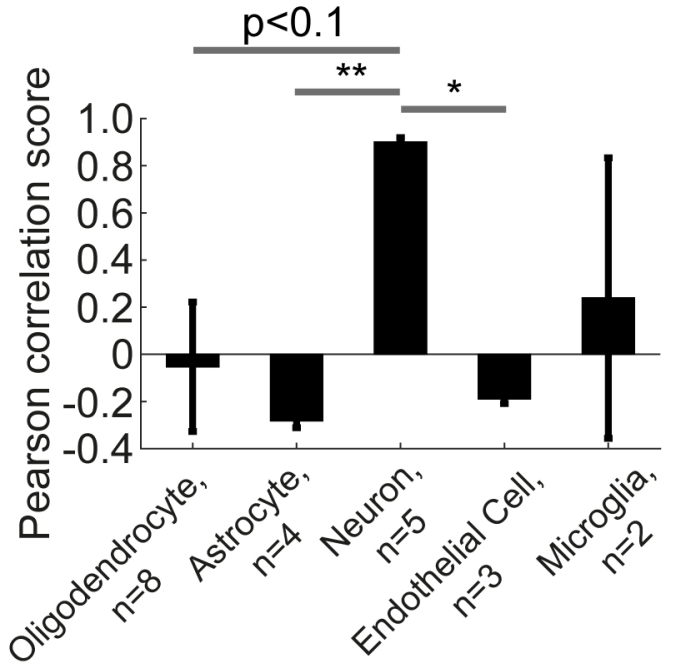

Cell Type

Figure S3

dmist_Dr

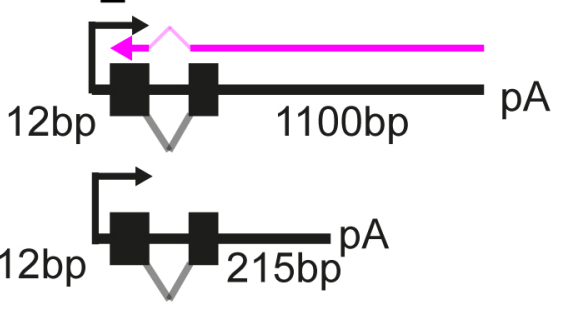

Dmist_Mm

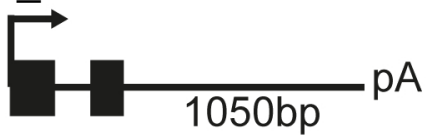

$0.5 \mathrm{~mm}$ 
GioRxiv preprint doi: https://doi.org/10.1101/2020.11.18.388Bd; this version posted December 6, 2020. The copyright holder for this -preprint (which was not certified by peer review) is the author/funder ${ }^{-w h o}$ has granted bioRxiv a license to display the preprint in

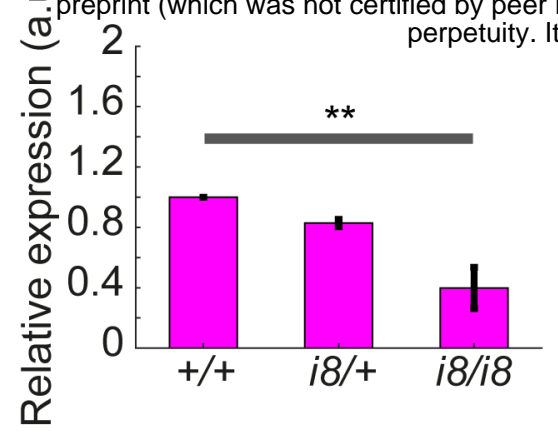

C)

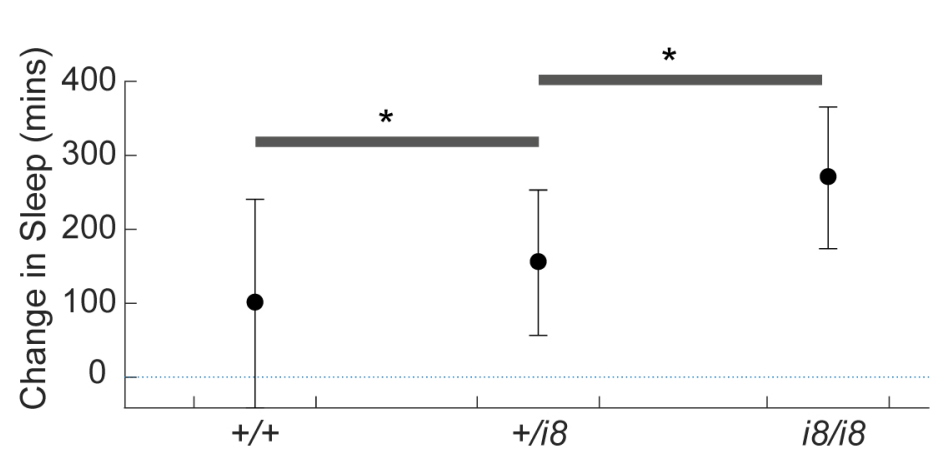

D)
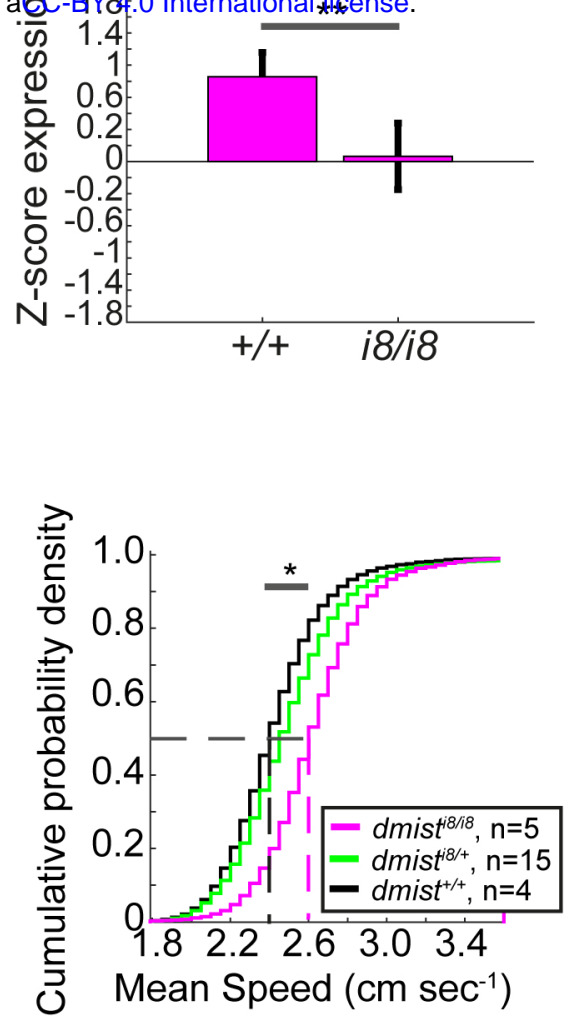

Figure S4 